\title{
Sensitivity analysis and implications for surface processes from a hydrological modelling approach in the Gunt catchment, high Pamir Mountains
}

\author{
E. Pohl ${ }^{1}$, M. Knoche ${ }^{2}$, R. Gloaguen ${ }^{1,3}$, C. Andermann ${ }^{4}$, and P. Krause ${ }^{5}$ \\ ${ }^{1}$ Remote Sensing Group, Geology Institute, Technische Universität Bergakademie Freiberg, \\ B.-von-Cotta-Str. 2, 09599 Freiberg, Germany \\ ${ }^{2}$ Helmholtz Centre for Environmental Research (UFZ), Halle, Germany \\ ${ }^{3}$ Remote Sensing Group, Helmholtz Institute Freiberg of Resource Technology, Freiberg, Germany \\ ${ }^{4}$ Helmholtz Centre Potsdam, German Research Centre for Geosciences (GFZ), Potsdam, Germany \\ ${ }^{5}$ Gewässerkundlicher Landesdienst, Hochwassernachrichtenzentrale, \\ Thüringer Landesamt für Umwelt und Geologie (TLUG), Jena, Germany
}

Correspondence to: E. Pohl (eric.pohl@geo.tu-freiberg.de)

Received: 30 October 2014 - Published in Earth Surf. Dynam. Discuss.: 15 December 2014

Revised: 26 June 2015 - Accepted: 3 July 2015 - Published: 23 July 2015

Abstract. A clear understanding of the hydrology is required to capture surface processes and potential inherent hazards in orogens. Complex climatic interactions control hydrological processes in high mountains that in their turn regulate the erosive forces shaping the relief. To unravel the hydrological cycle of a glaciated watershed (Gunt River) considered representative of the Pamir Mountains' hydrologic regime, we developed a remotesensing-based approach. At the boundary between two distinct climatic zones dominated by the Westerlies and Indian summer monsoon, the Pamir Mountains are poorly instrumented and only a few in situ meteorological and hydrological data are available. We adapted a suitable conceptual distributed hydrological model (J2000g). Interpolations of the few available in situ data are inadequate due to strong, relief-induced, spatial heterogeneities. Instead of these we use raster data, preferably from remote sensing sources depending on availability and validation. We evaluate remote-sensing-based precipitation and temperature products. MODIS MOD11 surface temperatures show good agreement with in situ data, perform better than other products, and represent a good proxy for air temperatures. For precipitation we tested remote sensing products as well as the HAR10 climate model data and the interpolation-based APHRODITE data set. All products show substantial differences both in intensity and seasonal distribution with in situ data. Despite low resolutions, the data sets are able to sustain high model efficiencies (NSE $\geq 0.85$ ). In contrast to neighbouring regions in the Himalayas or the Hindu Kush, discharge is dominantly the product of snow and glacier melt, and thus temperature is the essential controlling factor. Eighty percent of annual precipitation is provided as snow in winter and spring contrasting peak discharges during summer. Hence, precipitation and discharge are negatively correlated and display complex hysteresis effects that allow for the effect of interannual climatic variability on river flow to be inferred. We infer the existence of two subsurface reservoirs. The groundwater reservoir (providing $40 \%$ of annual discharge) recharges in spring and summer and releases slowly during autumn and winter, when it provides the only source for river discharge. A not fully constrained shallow reservoir with very rapid retention times buffers meltwaters during spring and summer. The negative glacier mass balance $\left(-0.6 \mathrm{mw}\right.$.e. $\left.\mathrm{yr}^{-1}\right)$ indicates glacier retreat, which will ultimately affect the currently $30 \%$ contribution of glacier melt to annual stream flow. The spatiotemporal dependence of water release from snow and ice during the annual cycle likewise implies spatiotemporally restricted surface processes, which are essentially confined to glaciated catchments in late summer, when glacier runoff is the only source of surface runoff. Only this precise constraint of the hydrologic cycle in this complex region allows for unravelling of the surface processes and natural hazards such as floods and landslides as well 
as water availability in the downstream areas. The proposed conceptual model has a tremendous importance for the understanding of the denudation processes in the region. In the Pamirs, large releases of running water that control erosion intensity are primarily controlled by temperature and the availability of snow and glaciers, thus making the region particularly sensitive to climatic variations.

\section{Introduction}

The Amu Darya, the main river draining the Pamir Mountains (hereafter the Pamirs) to the west, provides water resources for hydropower and irrigation along its way to the Aral Sea. Its various tributaries originate in the high mountains and experience wide-ranging climatic, topographic, and tectonic settings (Fuchs et al., 2013, 2014b). The Pamirs are located in the transition zone between the Westerlies in the west (in the winter half-year) and the Indian summer monsoon (ISM) in the south (in the summer half-year) (Fuchs et al., 2013; Aizen et al., 2009; Syed et al., 2006; Palazzi et al., 2013; Mischke et al., 2010). This unique setting make the Pamirs an outstanding natural laboratory to study aspects of climate variability, hydrologic response, and governed Earth surface processes under different climatic influences. The hydrological regime is reported to be snowand glacier-melt-dominated (Lutz et al., 2014; Kure et al., 2013; Tahir et al., 2011), albeit quantitatively largely unconstrained. Increasing demand for water and assumed changes in hydrological regimes of glaciated catchments with respect to a change in climatic conditions (Immerzeel et al., 2009; Hagg et al., 2013), as well as the inherent increased risks, demand for a better understanding of the processes governing surface flow in the region.

Because water acts as the main transport agent for sediments out of mountain belts (e.g. Milliman and Syvitski, 1992; Galy and France-Lanord, 2001) and plays a crucial role in the global carbon cycle (Maher and Chamberlain, 2014), sound estimates of the hydrological water balance and water components are also of fundamental importance for Earth surface processes. The primary control of tectonically driven topographic steepness on erosion suggests that changes in water availability are balanced by complex interactions between channel steepness and width, as well as concentrated sediment transport (Burbank et al., 2003; Scherler et al., 2014). But hydrology-related surface processes are manifold, including frost cracking intensities based on available water content (e.g. Andersen et al., 2015; Egholm et al., 2015), sediment mobilisation from snowmelt (Gao et al., 2014; Iida et al., 2012), glacier melt as a transport agent for sediment (Chernova, 1981; Ali and De Boer, 2010), river incision (Snyder et al., 2003; Lague et al., 2005), landslide triggering due to soil moisture content (Iverson, 2000; Dietrich et al., 1992), and suspended sediment transport in rivers (Andermann et al., 2012a, c; Dadson et al., 2003; Milliman and Syvitski, 1992). Therefore, obtaining spatiotemporal knowl- edge about water mobilisation in quantity and quality can provide further insights into the effects of climate and climate variability on mountain evolution (Champagnac et al., 2012; DiBiase and Whipple, 2011; Montgomery and Brandon, 2002). It would also allow for improved hazard risk assessment, which often relies on long-term projections of temperature increase and their effect on melting processes (Gruber and Mergili, 2013).

There is a consensus in the characteristic change in the hydrologic regime along the Himalayan front from rainfall to snow- and glacier-melt-dominated systems towards the west (Xiao et al., 2002; Bookhagen and Burbank, 2010; Lutz et al., 2014; Immerzeel et al., 2009). The few hydrologic studies in the Pamirs are hence basically glacier melt/snowmelt-runoff models that relied on in situ data (Hagg et al., 2007) and, more recently, on GCM (global climate model) data output (Kure et al., 2013; Hagg et al., 2013; Lutz et al., 2013) including future climate change scenarios. In contrast with the qualitatively agreeing hydrological studies, studies focusing solely on glaciers in the Pamirs show ambiguous results. Gardelle et al. (2013), for example, show a slight mass gain for glaciers in the Pamirs and also the Karakoram region for the last decade. Conversely, Lutz et al. (2013) and Sorg et al. (2012) report negative glacier mass balances for the Abramov Glacier in the north-eastern part of the Pamirs, however for a slightly earlier time period.

The different climatological settings between the Pamirs and the Himalayan escarpments stand in contrast to surprisingly similar regional erosion rates (Herman et al., 2013) for the last 2 million years. While order-of-magnitude-higher precipitation amounts in the Himalayas do not allow for a clear picture of how climate defines landscape evolution (Godard et al., 2014), the much drier climate in the Pamirs provides fundamentally different boundary conditions and suggests water availability as a limiting factor (Fuchs et al., 2014b). Precipitation intensities alone, however, cannot solve the discrepancy of intensities between hillslope erosion and river incision in the Pamirs (Fuchs et al., 2014a, b). Obtaining detailed spatiotemporal information from hydrological modelling is bound to an accurate assessment of forcing parameters. These are required with a matching spatiotemporal distribution, and hence remote sensing or GCM data provide an advantage over in situ data or the lack thereof, which is a major challenge in data-scarce regions such as the Pamirs.

When downscaling of often coarse GCM or remote sensing data is required, a proper transfer function is needed. This is not trivial in mountainous regions. Wood et al. (2004) give 
a good example of how diverse results can be if different downscaling approaches are applied in heterogenous areas, leading to over- or underestimation by a few hundred percent. The same is also true for the interpolation of in situ data, depending on what temperature lapse rates and precipitation gradients are applied (Immerzeel et al., 2014). Furthermore, the large differences in GCM and remote sensing data sets (Palazzi et al., 2013; Ménégoz et al., 2013) call for a validation with in situ data, which might not always be available. Newly developed regional climate models (RCMs), such as HAR10 (Maussion et al., 2014), help in preventing inaccurate interpolation. But available time spans and spatial coverage are limited. This is due to the high computational expense that is needed to create such data sets. The abundance and increasing accuracy in GCMs, RCMs, and remote sensing data has led to their greater use in hydrological modelling (Khan et al., 2011; Awange et al., 2011; Liu et al., 2012; Bookhagen and Burbank, 2010) and glacier evolution studies (Gardelle et al., 2012, 2013; Lutz et al., 2014; Sorg et al., 2012). In cold, arid, mountainous regions, GCMs are often favoured over remote sensing data. This is due to difficulties in snowfall (Prigent, 2010) and snow water equivalent (SWE) retrieval (Takala et al., 2011; Tong et al., 2010) from space. Furthermore, direct measurement of ground air temperature from space is not possible. Remote sensing land surface temperatures (LSTs) are, however, being used, for example, to derive temperature lapse rates for interpolation of in situ data (Liu et al., 2012) or the calculation of evaporation (Samaniego et al., 2011). Use of LSTs as a proxy for ground air temperature has also been established, however only in lowlands (Deus et al., 2013).

This paper concentrates on resolving the hydrologic cycle in the high Pamirs, using a conceptual, semi-distributed hydrological model. This approach is very demanding due to data scarcity, and hence a special focus is directed toward the validation of independent daily raster data from remote sensing, climate models, and combined products. The limited possibilities and problems (Tustison et al., 2001) in validating the specific raster data sets with in situ measurements are accounted for by an analysis of their influence on systematic effects in the resulting hydrological models. We ultimately aim for a conceptual description of the hydrological cycle in the Gunt River basin in order to understand and quantify the main drivers of erosion and incision in the Pamirs. Uncertainties in the data and model are discussed in detail. The quantification of the different water components is of fundamental relevance for understanding surface processes (mass wasting, glacier lake outburst floods, etc.), and eventually for understanding the controlling factors of denudation rates. Here, we consider the Gunt River basin as representative for the central Pamirs. We describe potentials and limitations of hydrological modelling under data scarcity as a tool for understanding erosive processes. Finally, we use obtained results on moisture supply, as well as water mobilisation, to infer a conceptual model for expected surface processes in the Pamirs.

\section{Study area}

The Pamirs are very heterogenous in terms of moisture supply and relief. This makes it difficult to carry out a representative assessment of their hydrological behaviour based on a single catchment. The Pamirs are mainly influenced by two atmospheric circulation systems - dominant Westerlies in the western part and Westerlies in combination with the northward ISM or in combination with northern intrusions in the eastern part (Aizen et al., 2009; Palazzi et al., 2013; Syed et al., 2006; Fuchs et al., 2013; Mischke et al., 2010). There is no full consensus about the moisture source in the very arid eastern part. Schiemann et al. (2007), for example, reported that no spillover of moisture occurs in the Pamir during strong ISM. Whether this holds true for weak ISM is not reported. Independent of the source, the eastern part of the Pamirs receives generally less precipitation and a higher proportion of summer over winter precipitation than the western part. In situ precipitation data from 2000 and 2002 to 2006 were provided by the State Administration for Hydrometeorology of Tajikistan (SAHT). Old equipment implies a possible source of error. An exception is site Navabad, which is equipped with an automatic precipitation gauge. In situ data show a distinct intra-annual distribution with a precipitation maximum in the winter halfyear for the westernmost stations, Ishkashim, Khorog, Navabad, and Dzaushangoz (Fig. 1). For the easternmost stations, Murghab and Shaimak, a slight maximum in the summer half-year is noticeable. Summer precipitation reaching the eastern part of the Pamirs (Murghab and Shaimak) provides less precipitation compared to the Westerlies in the western part (Khorog and Navabad) in winter. This negative west-east precipitation gradient has also been reported by Fuchs et al. (2013). According to Köppen-Geiger classification, Khorog, Navabad, and Ishkashim are characterised by a cold climate with hot and dry summers (Dsa), while Dzaushangoz and more eastern stations correspond to an arid, cold, desert climate (BWk) (Peel et al., 2007). Land cover is mainly barren or sparsely vegetated $(67.6 \%)$ and grassland $(24.0 \%)$, and about $7.5 \%$ of the catchment area is covered by glaciers (see Sect. 4.1.3 for derivation). Glaciers are mainly located in the moister western part, especially along the Rushan Range (Fig. 2). The Randolph Glacier Inventory (Arendt et al., 2014) shows some inconsistencies in mapping type and is incomplete for the study area, which makes the assessment of glacier sizes difficult. However, the available data suggest individual glacier sizes ranging from 1 to $30 \mathrm{~km}^{2}$. Relief shows likewise strong differences with a west-east gradient. In the west, strongly incised rivers and high local relief are dominant, whereas in the east a preserved plateau dominates the landscape (Fuchs et al., 2013, 2014b).

We selected the Gunt catchment, including its main tributary (the Shakhdara River), located in the central Pamirs (Fig. 2), because it comprises these gradients in both moisture supply and relief. The catchment is located in the south 

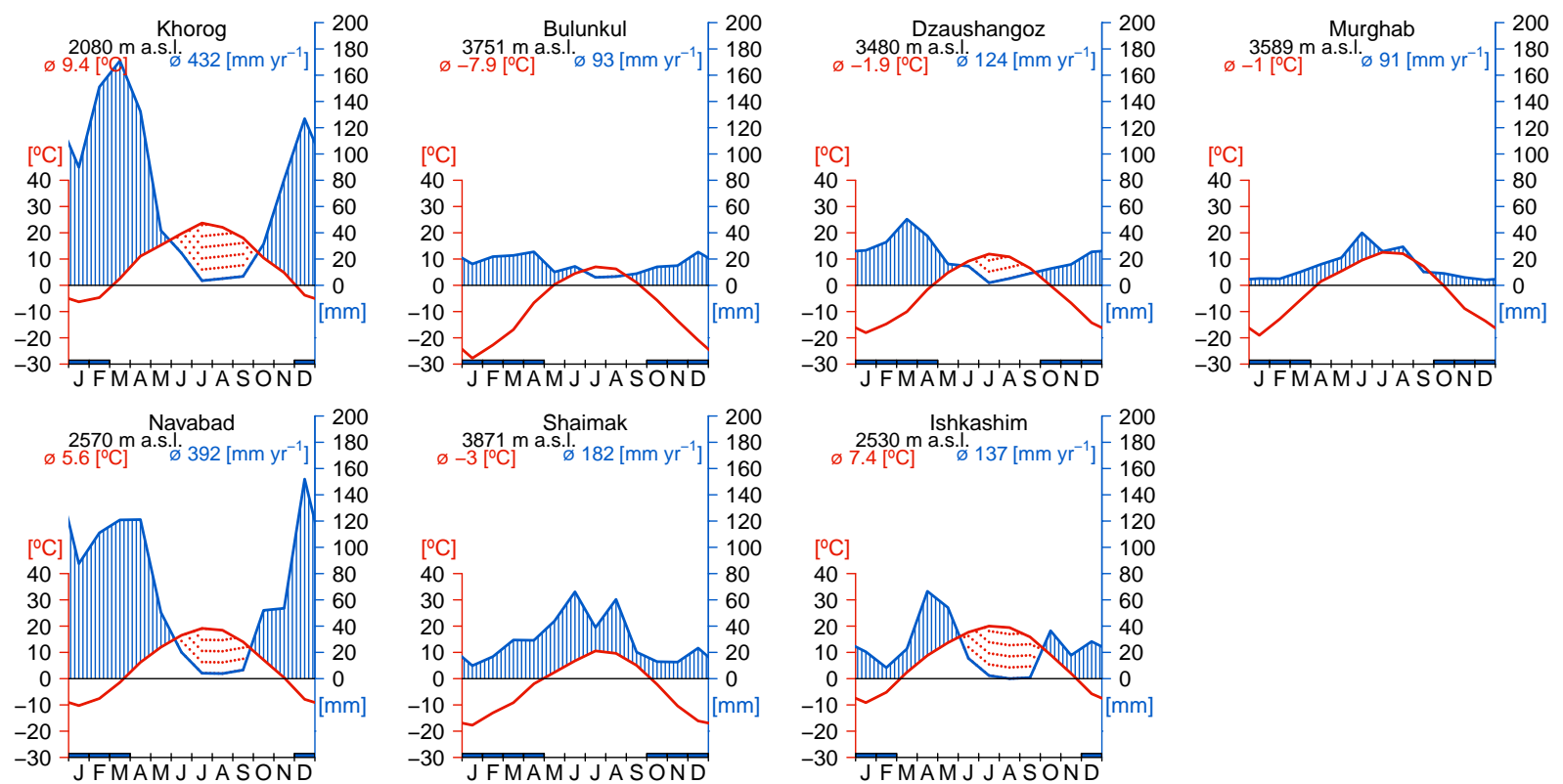

Figure 1. Climate diagrams for the available meteorological stations with precipitation amounts (blue) and temperature (red). The westernmost stations, Khorog, Navabad, and Ishkashim, show a distinctive precipitation maximum in winter. The influence of Westerlies in the winter half-year decreases with altitude towards the east (Bulunkul, Murghab, Shaimak). There is an increase in precipitation during monsoon season with peak in summer for Murghab and Shaimak in the easternmost part.

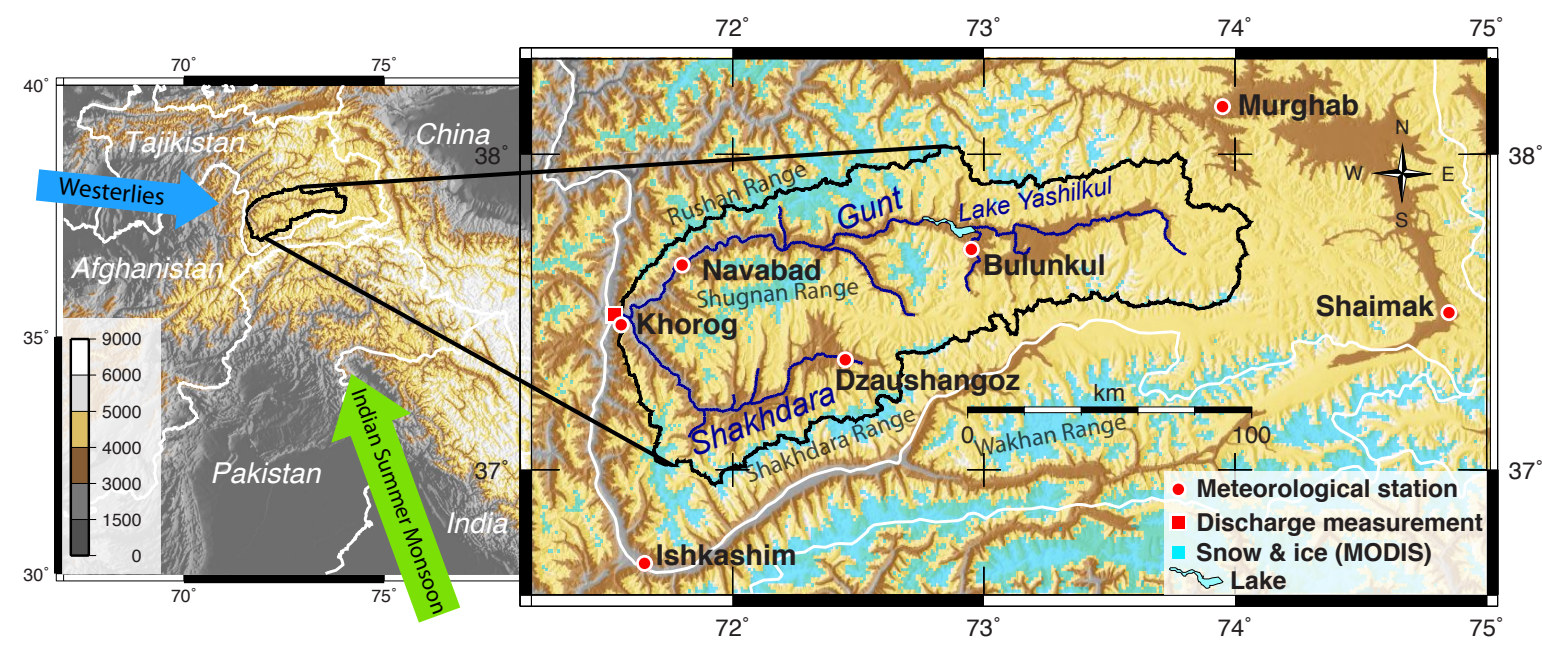

Figure 2. Study area in the Tajik Pamirs with catchment area of the Gunt and Shakhdara rivers and available meteorological stations and discharge measurement location. Monsoon and Westerlies are indicated by arrows according to Zech et al. (2005) and Fuchs et al. (2013). MODIS MCD12Q1 land cover class for permanent ice and snow cover (light blue) as a proxy for glacier extent.

of the Gorno-Badakhshan Autonomous Oblast (GBAO) in south-eastern Tajikistan $\left(37^{\circ} \mathrm{N}, 73^{\circ} \mathrm{E}\right)$, in the Pamirs (Fig. 2). It extends over about $14000 \mathrm{~km}^{2}$. The rivers Gunt and Shakhdara connect before they flow through Khorog, where an available gauging station is located. The catchment is characterised by elevations ranging between $2080 \mathrm{~m}$ a.s.l. at the catchment outlet and up to 6700 ma.s.l. at Karl Marx Peak in the Shakhdara Range. The average elevation is about 4300 ma.s.l. The higher elevations bound the catchment, but high elevations also occur within the catchment in the Shugnan Range, which divides the Gunt and Shakhdara subbasins. Four meteorological stations are located in the watershed, providing precipitation and temperature data for comparison and calibration of remote sensing data. Three further stations are located in the vicinity of the watershed for additional ground validation (Fig. 1). All meteorological stations are located in the valleys (see Fig. 1 for elevations), which makes the assessment of meteorological conditions at 


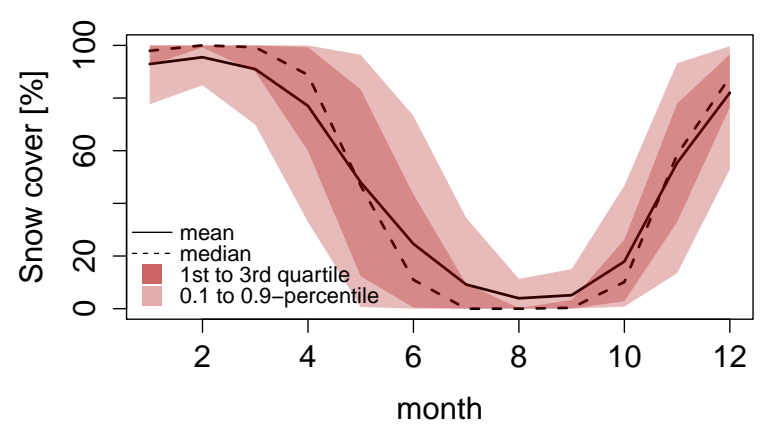

Figure 3. Monthly average snow cover in the Gunt catchment. Data basis is MOD10CM (Hall et al., 2006) monthly snow cover for the period 2001 to 2012.

high elevations impossible. Even though the eastern stations are generally higher in altitude and receive less precipitation than those in the western part, there is no evident relationship between altitude and precipitation.

With an average altitude of 4300 ma.s.l., the region shows a long-lasting snow cover period (Fig. 3) with an average snow cover of $>50 \%$ from November until March (Immerzeel et al., 2009; Pu et al., 2007; Dietz et al., 2014). A negative temperature gradient is apparent along the westeast gradient in precipitation and relief. Station Bulunkul shows exceptionally low values of both precipitation and temperature. This is likely induced by its location, which is surrounded by mountains in the close proximity. Due to the long-lasting snow cover and the bulk of precipitation provided as winter precipitation, snowmelts are expected to play an essential role in the water balance. Even though the easternmost parts receive higher fractions of summer over winter precipitation, temperatures below freezing temperature at valley floor level during most of the year (Fig. 1) suggest a substantial amount of precipitation received as snow. While there is a pronounced west-east gradient in precipitation, no precipitation lapse rate is evident from the limited in situ data (Fig. 1).

Daily discharge measurements have been conducted in Khorog (Fig. 2) with few exceptions since 1960. We cannot independently assess the quality of the measurements, but old equipment that has not been maintained since the independence of Tajikistan, along with old rating curves, imply a possible source of error. Anthropogenic influences on the observed discharge are most probably minor but hard to assess. A hydropower plant and a lake regulation station are in operation near site Navabad and at Lake Yashilkul (see Fig. 2), respectively. While the amount of water used by the power plant would return to the river without change in quantity and without noticeable recession, the assessment of lake discharge is difficult. Discharge records from the 1960s for Khorog show similar winter discharge to the 2000s. This allowed us to assume that the water usage from the hydropower plant and the lake regulation do not affect the hydrologi- cal cycle much. Furthermore, a few years of data for a subcatchment of the Gunt River (gauging the Gunt river itself $\approx 50 \mathrm{~km}$ downstream of Lake Yashilkul) show winter discharge of $\approx 8 \mathrm{~m}^{3} \mathrm{~s}^{-1}$, which makes up one-third of the discharge at Khorog in winter. This $8 \mathrm{~m}^{3} \mathrm{~s}^{-1}$ includes a few other sub-catchments, of which one contributes an additional $1-2 \mathrm{~m}^{3} \mathrm{~s}^{-1}$. This suggests that the overall contribution of lake discharge to the observed runoff is very low and that the observed winter discharge results mainly from groundwater discharge. Neither melt nor liquid precipitation is expected during winter due to low temperatures. Other anthropogenic influences include irrigation, which occurs during summer and almost exclusively in the valleys. According to the land cover classification used (see Sect. 4.1.3 for derivation), only $0.1 \%$ are croplands. Hergarten (2004) report irrigated land to account for only $0.38 \%$ in the Pamir region. To roughly estimate the impact of irrigation, we estimated the water consumption based on obtained model results for potential evapotranspiration, an irrigated area according to $0.38 \%$ land cover, and an assumed irrigation period between May and September. The resulting impact corresponds to $0.4 \%$ of the average annual discharge measured at Khorog.

The available discharge data for Khorog at the catchment outlet shows a general intra-annual pattern with very low and generally declining discharge from October to March. Lowest discharge occurs at the end of March $\left(\approx 30 \mathrm{~m}^{3} \mathrm{~s}^{-1}\right)$. In April, the discharge rapidly increases and shows strong variability until September, when discharge strongly attenuates. Peak discharge occurs in July $\left(\approx 290 \mathrm{~m}^{3} \mathrm{~s}^{-1}\right)$. Average discharge for the winter period (ONDJFM) is about $44 \mathrm{~m}^{3} \mathrm{~s}^{-1}$, and for the summer period (AMJJAS) about $164 \mathrm{~m}^{3} \mathrm{~s}^{-1}$. The average annual discharge is $3.48 \mathrm{~km}^{3} \mathrm{yr}^{-1}$ (i.e. $255 \mathrm{~mm} \mathrm{yr}^{-1}$ or $105 \mathrm{~m}^{3} \mathrm{~s}^{-1}$ ). Strong interannual variations in the summer hydrograph contrast with a low and rather constant winter hydrograph. This further suggests a high importance of snow and glacier melts for the hydrological cycle and a significant fraction of groundwater discharge in winter. The interannual discharge variability is high, e.g. $132 \mathrm{~m}^{3} \mathrm{~s}^{-1}$ in 2005 vs. $95 \mathrm{~m}^{3} \mathrm{~s}^{-1}$ in 2007. During fieldwork in March 2013, we observed that the inflow to Lake Yashilkul (3800 ma.s.l.) was entirely frozen. Likewise, interrupted streamflow is assumed for other high-elevation tributaries in winter and the entire catchment area east of Lake Yashilkul. The eastern part of the catchment is in a zone of potential permafrost (altitudes above $3800 \mathrm{~m}$ a.s.l.; Mergili et al., 2012). Hence, water release from permafrost or from sporadically frozen soils is assumed to play a role in the hydrological cycle.

\section{Methods}

We first present the hydrological model J2000g and its framework, JAMS (Jena Adaptable Modelling System), followed by a description of the input data and their structures thereafter. 


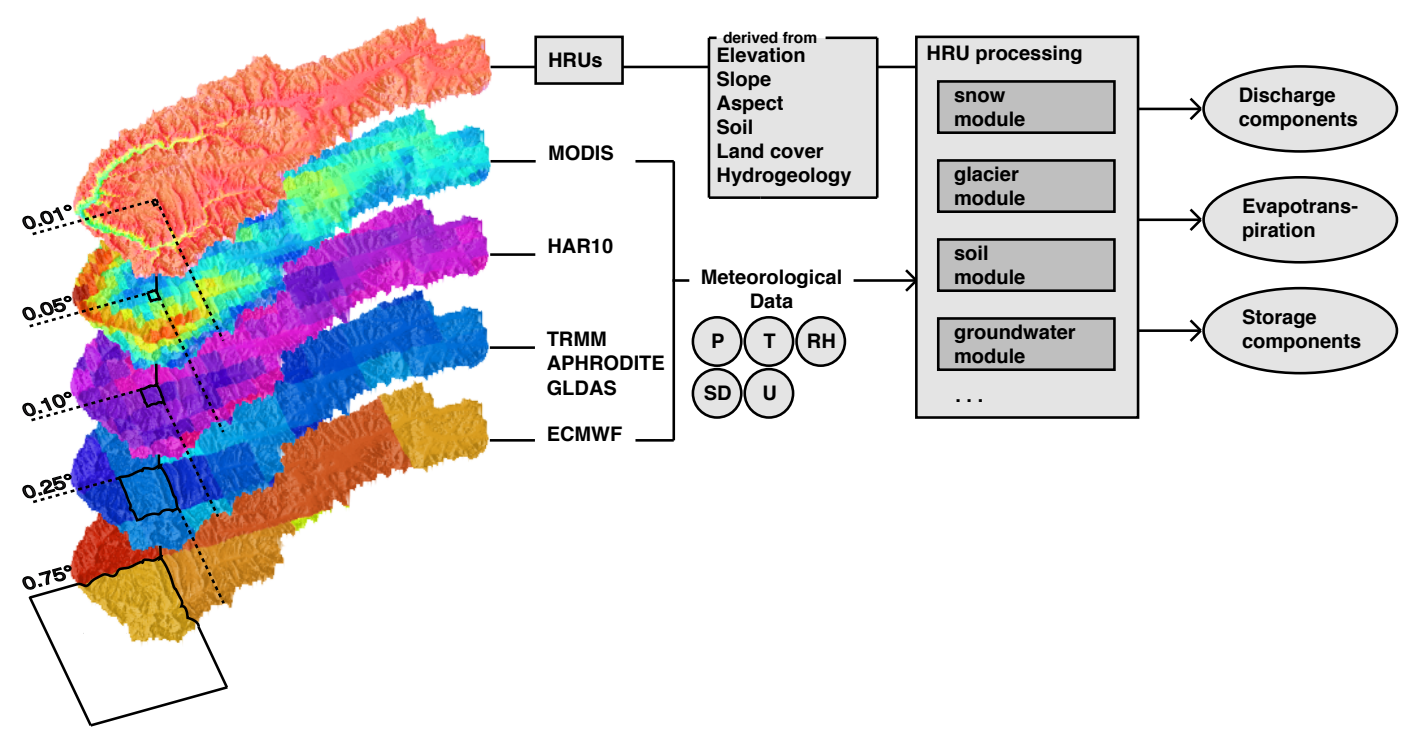

Figure 4. Schematic superimposition of different meteorological raster data with various spatial resolutions. Hydrological response unit (HRUs) have $1 \mathrm{~km} \times 1 \mathrm{~km}$ pixel size. Processing modules of the $\mathrm{J} 2000 \mathrm{~g}$ model take needed forcing data ( $P$ : precipitation; $T$ : temperature; RH: relative humidity; SD: sunshine hours; $U$ : near-ground wind speed) to be processed for each individual HRU. The final step is the output of discharge components, evapotranspiration, and storage changes.

\subsection{Hydrological modelling}

Depending on the area of interest, choices had to be made regarding the computational and distributional concept, as well as the model's temporal resolution. Daniel (2011) gives a good comparison of different frequently used models but the number of different models is simply too large to be covered entirely. The integration of raster data sets has been implemented in different models such as the MIKE SHE (Cooper et al., 2006; Liu et al., 2012) or CREST (Khan et al., 2011) models, and several more examples of raster data input are available (Merritt et al., 2006; Stahl et al., 2008; Wood et al., 2004). While each of these models has specific qualities, none of them globally outperforms the others. The majority of existing models require very specific and scarcely available information on specific properties of, for example, soils and plants. We only have limited information available about these properties. Hence, we chose the conceptual distributed hydrological model J2000g within the JAMS framework. The model is adapted to multi-scale hydrological studies and needs only a limited number of soil and plant properties, which also reduces the complexity of the calibration process. The benefit of higher simplicity contrasts an apparent simplification of physical processes related to soil and water routing dynamics. An important feature of $\mathrm{J} 2000 \mathrm{~g}$ is the possibility of using raster data sets as meteorological input (Krause et al., 2010) and adapting some model components to the study area. Similar approaches have been successfully implemented not only in flat, semi-arid terrain (Deus et al., 2013) but also in glaciated, mountainous regions (Nepal et al., 2014).

\subsection{The JAMS framework and the hydrological model $\mathrm{J} 2000 \mathrm{~g}$}

The hydrological model J2000g (Kralisch et al., 2007; Krause and Hanisch, 2009) is modular-based and allows, to a certain degree, for the interchange of specific modules to fit the user's needs. It uses a smaller number of calibration parameters than the fully distributed J2000 model, which has been successfully applied in the central Himalayas (Nepal et al., 2014). We chose J2000g over J2000 due to limited information on soil and aquifer properties. J2000g requires spatially distributed information about relief, land use, soil type, and hydrogeology to estimate specific attribute values for each entity or hydrological response unit (HRUs) (Krause and Hanisch, 2009). The required meteorological inputs are precipitation, minimum, maximum and average temperature, sunshine duration, wind speed, and relative humidity from one or more point sources. Usually, these data are then interpolated to provide data for each HRU. We avoid the interpolation thanks to area-wide coverage of raster data.

A conceptual outline of the modelling approach with superimposed meteorological data for the study area, as well as their different spatial resolutions, is given in Fig. 4. For each HRU, a set of modules calculate the discharge components, evapotranspiration, and storage changes. To improve model efficiency, parameters (Table 1) can be adjusted to account for inaccurately set values of soil, plant, and hydrogeological properties. The substantial processing routine of J $2000 \mathrm{~g}$ consists of the calculation of net radiation based on Allen et al. (1998), followed by the calculation of potential evapotranspiration (potET) after Penman-Monteith. The discrimination 
Table 1. Model calibration parameters and their value range. Parameterisation values apply to all HRUs unless specified differently.

\begin{tabular}{|c|c|c|}
\hline Parameter & Value range & Description \\
\hline$T_{\text {base }}$ & $-8-8^{\circ} \mathrm{C}$ & Threshold temperature for freezing/melting of non-glaciated HRUs \\
\hline $\mathrm{TMF}_{\mathrm{S}}$ & $0-8 \mathrm{~mm}^{\circ} \mathrm{C}^{-1} \mathrm{day}^{-1}$ & Degree-day factor for snowmelt of non-glaciated HRUs \\
\hline$T_{\text {base }_{\mathrm{g}}}$ & $-5-7^{\circ} \mathrm{C}$ & Threshold temperature for freezing/melting of glaciated HRUs \\
\hline $\mathrm{TMF}_{\mathrm{gs}}$ & $0-8 \mathrm{~mm}^{\circ} \mathrm{C}^{-1} \mathrm{day}^{-1}$ & Degree-day factor for snowmelt of glaciated HRUs \\
\hline $\mathrm{TMF}_{\mathrm{gi}}$ & $0-8 \mathrm{~mm}^{\circ} \mathrm{C}^{-1} \mathrm{day}^{-1}$ & Degree-day factor for ice melt of glaciated HRUs \\
\hline ETR & $0-0.7$ & $\begin{array}{l}\text { Evapotranspiration reduction factor accounting for increasing resistance against } \\
\text { evapotranspiration with decreasing soil moisture content }\end{array}$ \\
\hline maxPerc & $1 \times 10^{-4}-20$ & Scaling factor for maximum percolation rates \\
\hline LVD & $0-5$ & Lateral-vertical distribution; lower values for more vertical and less lateral flow \\
\hline FCA & $0-2$ & Field-capacity adaption; lower values for less field capacity \\
\hline gwStorAlpha & $0-1$ & $\begin{array}{l}\text { Distribution coefficient of percolation to either groundwater storage components; } \\
\text { lower values for higher contribution to deep groundwater and less contribution to } \\
\text { fast recession component }\end{array}$ \\
\hline $\mathrm{GWK}_{1}$ & $0-100$ & Recession parameter for the first linear storage (fast subsurface flow) \\
\hline $\mathrm{GWK}_{2}$ & $100-400$ & Recession parameter for the second linear storage (deep groundwater) \\
\hline
\end{tabular}

of precipitation provided as rain or snow is based on a threshold value, $T_{\text {base, }}$ which is determined in the calibration process. Snow and ice melt are calculated using a degree-day method based on time-degree factors (TMFs) according to

melt $\left[\mathrm{mmday}^{-1}\right]=\mathrm{TMF} \times\left(T_{\text {air }}-T_{\text {base }}\right)$,

where $T_{\text {air }}$ is the air temperature. A total of three TMFs are introduced in the model: one for snow of regular HRUs, i.e. non-glaciated HRUs; one for snow of glacier HRUs (see Sect. 4.1.3); and one for ice of glacier HRUs. Meltwater originating from snow and ice of glacier HRUs is considered as glacier meltwater $Q_{\text {glac }}$. Glacier mass balance is calculated as the difference of glacier HRUs' precipitation input and the sum of glacier HRUs' snow and ice melt (i.e. $Q_{\text {glac }}$ ), as well as actET. We introduce two independent TMFs for snow because of several dependencies that we can scarcely assess. These include increases in TMF with increasing solar radiation and elevation, and with decreasing proportions of sensible heat flux and albedo (Hock, 2003). Furthermore, we cannot validate at high elevation the temperature data sets used. Hence, this approach provides a more detailed analysis of effects of individual data sets. Glaciers in J2000g have no defined volume and could theoretically melt or store infinite amounts of water. While this does not, of course, represent the actual conditions, it allows for comparison of overestimating and underestimating precipitation data sets due to the compensation of the water balance by means of increased glacier runoff. Meltwater and liquid precipitation are transferred to the soil water module, which consists of a simple water storage with a capacity (calibration factor FCA) derived from the field capacity of individual HRUs. Water stored in the soil, within the range of the storage capacity, can only leave through evapotranspiration. The calculated actual evapotranspiration (actET) depends on the saturation of the soil water storage, the potET, and a calibration parameter,
ETR. The soil storage must be saturated before runoff generation can start. The amount of water exceeding the soil water storage is distributed into a lateral and a vertical component, based on the HRU's slope and the calibration factor LVD (lateral-vertical distribution). The vertical component is considered as percolation and is transferred to the groundwater storage component. The maximum amount of percolation is limited by the calibration parameter maxPerc. Base flow $Q_{\text {bas }}$ is simulated with a linear outflow routine adjusted by the recession parameter GWK (groundwater turnover time), which is defined as

GWK [days] $=\frac{V}{Q}$,

where $V$ is the storage volume in mm, and $Q$ is the outflow from this storage in $\mathrm{mm} \mathrm{day}^{-1}$. The lateral excess water is direct runoff $Q_{\text {dir }}$ without retardation. J2000g's soil module expects well-evolved soils with pronounced storage capacities, which is not the case in the Pamirs. Instead, various sediment deposits, such as alluvial fans, and reworked moraine material with high inclinations along the hillslopes characterise the region. These sediment deposits were assumed to show only a short but noticeable retardation of water input, and to have rather small storage capacities. We account for that by including a second linear storage component in addition to the linear storage for the groundwater component. Because $\mathrm{J} 2000 \mathrm{~g}$ needs the soil module as an interface between atmospheric (and melt) water input and the groundwater component, this second linear storage is an addition to these components. The additional component allows the model, if necessary, to avoid full or no retardation of water in soils and instead determine the recession in the calibration process. The calibration parameter for the fast recession component is GWK1, and GWK2 for the second, slow recession component. Because the fast recession component corresponds 
to the groundwater module in its design, J2000g treats both components as groundwater storages, and hence we use the terms $Q_{\text {bas1 }}$ and $Q_{\text {bas2 }}$ for the resulting discharge from these components. Percolation water is distributed into the two linear storage components based on the distribution coefficient gwStorAlpha. Finally, $Q_{\text {dir }}$ and the two $Q_{\text {bas }}$ components of each HRU are summed up to give the total simulated streamflow $Q_{\text {tot }}$.

$\mathrm{J} 2000 \mathrm{~g}$ does not have water routing through individual HRUs in a topological context like more complex models, such as J2000. As a result, the J2000g model cannot account for losses and transformations during runoff concentration. We accept this limitation due to insufficient information available about soil and hydrogeological properties and assumed quick runoff on steep slopes without complex reinfiltration processes between HRUs.

\section{Data}

We use HRUs based on raster cells. All needed parameters were processed in the $\mathrm{R}$ environment ( $\mathrm{R}$ Core Team, 2014) and finalised using open-source GIS software (GRASS-GIS and QGIS). We use a spatial resolution of $0.01^{\circ}$ to balance the computational expense vs. the resolving power of some data sets. Linkage of the meteorological raster data to the single HRUs was achieved by overlay. The static parameters are considered constant over the time of the study and are provided once. The model runs with a daily temporal resolution. Meteorological data were either directly provided at daily resolution or downscaled if they provided a higher resolution. The parameter and meteorological input data used in this work are described in the following two sections. An overview of these data, as well as their spatial and temporal resolution, is given in Table 2.

\subsection{Geographical model parameters}

\subsubsection{Elevation, slope, and aspect}

Elevation is taken from an SRTM (Shuttle Radar Topography Mission) DEM (digital elevation model) (Jarvis et al., 2008) with $90 \mathrm{~m}$ resolution (http://srtm.csi.cgiar.org). Slope and aspect are derived from this DEM with GIS software.

\subsubsection{Soil}

Soil data are taken from the Harmonized World Soil Database (HWSD) (FAO et al., 2009) and from the Atlas of the Republic of Tajikistan (Narzikulov and Stanjukovič, 1968). A combination of the HWSD database and the classification from the atlas that referred to soils by occurrence (e.g. alpine meadow or high-mountain desert) was used to parameterise the soil map. Leptosoils are the predominant soils. The HWSD provides grain size distributions for the first $30 \mathrm{~cm}$ for all leptosoil subtypes, and depths from 30 to
$100 \mathrm{~cm}$ for most others. To derive the field capacities that represent a parameter of the $\mathrm{J} 2000 \mathrm{~g}$ model, empirical tables of the soil mapping manual Bodenkundliche Kartieranleitung (KA5) (Ad-hoc-Arbeitsgruppe Boden, 2005) were used. First, the bulk density given by the HWSD was used to derive the dry density (Ad-hoc-Arbeitsgruppe Boden, 2005, p. 126). Then the soil type was determined by using a soil type diagram (Ad-hoc-Arbeitsgruppe Boden, 2005, p. 142), in which the grain size distributions were used to derive the according soil types. The field capacities were derived as a function of soil type and dry density (Ad-hoc-Arbeitsgruppe Boden, 2005, p. 344). In combination with the information from the HWSD, the depth of the soils in $\mathrm{cm}$ and the total water capacity in mm were extracted. We assume vertical homogeneity of all soils for the parameterisation of soil water capacity.

\subsubsection{Land use and glacier extent}

For land use, we extract the IGBP (International GeosphereBiosphere Programme) classification scheme, included in the combined MODIS data set MCD12Q1 (Strahler et al., 1999). We use the 2005 classification, which marks the middle of the investigation period. The Gunt and Shakhdara catchments are sparsely vegetated by xeromorphic dwarf shrubs. Casual field observations in August 2011 have shown that vegetation diversity and vegetation cover are low along the main stem of the Gunt River. Vanselow and Samimi (2014) used a satelliteimagery-based approach to model vegetated land cover in the eastern Pamirs (Murghab and Alichur). They estimated half of the region to have $<15 \%$ vegetated land cover, which includes the extensive alpine meadows in the vicinity of the main stem of the rivers. We observed only closed vegetation cover at these spatially limited alpine meadows on the plateau, in the eastern part of the catchment $(\approx 3800 \mathrm{~m}$ a.s.l. $)$. In combination with the long-lasting snow cover, we assume vegetation to have only a minor impact on the overall water balance.

The major classes of the 2005 IGBP classification for the studied catchment are $7.5 \%$ permanent snow and ice, $24.0 \%$ grassland, and $67.6 \%$ barren or sparsely vegetated area. We use the permanent snow and ice class as a proxy for glaciated areas. This bares the possibility of wrongly assessing snow cover as glacier extent, given that melting conditions prevented a snow line retreat to the glacier termini or perennial snow cover. However, Scherler et al. (2011) reported significant debris-covered glacier areas in the Hindu Kush and Karakoram regions which cannot be detected by MODIS. A comparison of the 2005 classification for permanent snow and ice with the Randolph Glacier Inventory (RGI) shows partially good agreement. A problem with the RGI is, however, an inconsistent and partly missing classification in, for example, the Shugnan Range. This led us to use the MCD12Q1 classification instead. Plants associated with the IGBP classes are derived from Agakhanyantz and Lopatin 
Table 2. Input used for derivation of HRUs and meteorological input data with specifications about temporal and spatial resolution. For static parameters the date of creation is given if available. SAHT is the State Administration for Hydrometeorology of Tajikistan and HWSD is the Harmonized World Soil Database. Resolutions of digitised SAHT and HWSD maps that are in vector format are roughly approximated. For the actual modelling, hourly values were averaged or summed up to yield daily values.

\begin{tabular}{|c|c|c|c|}
\hline Input & Data set & Spatial resolution & Temporal resolution \\
\hline \multicolumn{4}{|c|}{ Parameter data } \\
\hline Elevation, slope, aspect & SRTM DEM & $90 \mathrm{~m}$ & static (1999) \\
\hline Land use & MODIS MCD12Q1 & $500 \mathrm{~m}$ & static (2005) \\
\hline Soil & SAHT map/HWSD & $\approx 5 \mathrm{~km} / \approx 50 \mathrm{~km}$ (vector map) & static (NA/2009 HWSD) \\
\hline Hydrogeology & SAHT map & $\approx 5 \mathrm{~km}($ vector map $)$ & static (NA) \\
\hline \multicolumn{4}{|c|}{ Meteorological data } \\
\hline Precipitation & TRMM3B42 V7/APHRO_MA_V1101/HAR10 & $0.25^{\circ} / 0.25^{\circ} \approx 0.10^{\circ}$ & daily \\
\hline Temperature & MODIS MOD11C1 V5/HAR10 & $0.05^{\circ} \approx 0.10^{\circ}$ & daily \\
\hline Wind speed & GLDAS_NOAH025SUBP_3H & $0.25^{\circ}$ & 3-hourly \\
\hline Relative humidity & GLDAS_NOAH025SUBP_3H & $0.25^{\circ}$ & 3-hourly \\
\hline Sunshine duration & ECMWF Era-Interim & $0.75^{\circ}$ & 12-hourly \\
\hline
\end{tabular}

(1978) and Breckle and Wucherer (2006). The according plant characteristics are then taken from the online database PlaPaDa (Plant Parameter Data) (Breuer and Frede, 2003). These characteristics comprise values for albedo, stomata resistances, leaf area indices, plant heights, and root depths. For the different seasonal and monthly characteristics, the assumption was made that little to no plant transpiration would take place during the long-lasting snow cover from autumn to spring (Immerzeel et al., 2009). To simulate this effect, the stomata resistance values were increased from November to March.

\subsubsection{Hydrogeology}

Hydrogeological information was taken from the Atlas of the Republic of Tajikistan (Narzikulov and Stanjukovič, 1968). The study area comprises five lithologies and two other classes - one for ice/snow and one for lakes. The ice/snow extent differed from the land cover classification. Therefore we reclassified mismatching areas for snow/ice in the hydrogeological map according to nearest-neighbour adjacent lithologies. At this stage, we have no quantitative hydrogeological information and rely on some literature values (Batu, 1998) and assign maximum percolation rates between $20 \mathrm{~mm} \mathrm{day}^{-1}$ for magmatic rocks (including fractured rock aquifers) and $300 \mathrm{~mm} \mathrm{day}^{-1}$ for Quaternary sediments. During the optimisation process, $\mathrm{J} 2000 \mathrm{~g}$ calibrates the correction factor maxPerc.

\subsection{Meteorological data}

\subsubsection{Precipitation}

Based on the work of Palazzi et al. (2013) and Ménégoz et al. (2013), who both emphasise radical differences in precipita- tion data sets from various sources in the high mountains of Asia, we include a total of three precipitation data sets, one remote sensing product, one interpolated data set, and one climate model data set in order to assess their influence on the representation of the hydrological cycle. Evaluation of the data sets by comparison with in situ data is impeded by the point-wise character of rain/snow gauges on the one hand and area-averaged values of the raster data on the other (Tustison et al., 2001). Precipitation events taking place near the rain gauge might contribute to the data set but are not recorded for the in situ measurement. A moving rainstorm might also introduce a temporal error, because it will be recorded only within a restricted time frame at the measuring station. Furthermore, meteorological stations are located in the valleys. Hence, they cannot record advective precipitation at high altitude. Different spatial resolutions of the data sets used complicate a representative analysis even more. Correlation analyses carried out with in situ data, consequently, show no significant correlation on a daily basis. If intensities are added up to monthly values (Fig. 5), correlation increases, especially for the higher resolution data set. The differences in the data sets and few in situ data prevent an in-depth evaluation.

We will show later on that the most crucial aspect of any given precipitation data set is the total precipitation amount provided during the snow accumulation period (seasonal distribution). This amount determines the snow stock, which in return provides the boundary condition for melt. This allows all data sets, as long as winter precipitation provides a sufficient amount, to sustain the hydrological cycle with very similar results. We calibrate the data sets with in situ measurements and also apply correction factors (Table 3) to test effects of possibly wrong precipitation amounts. We justify the application of a large range of correction factors due to 

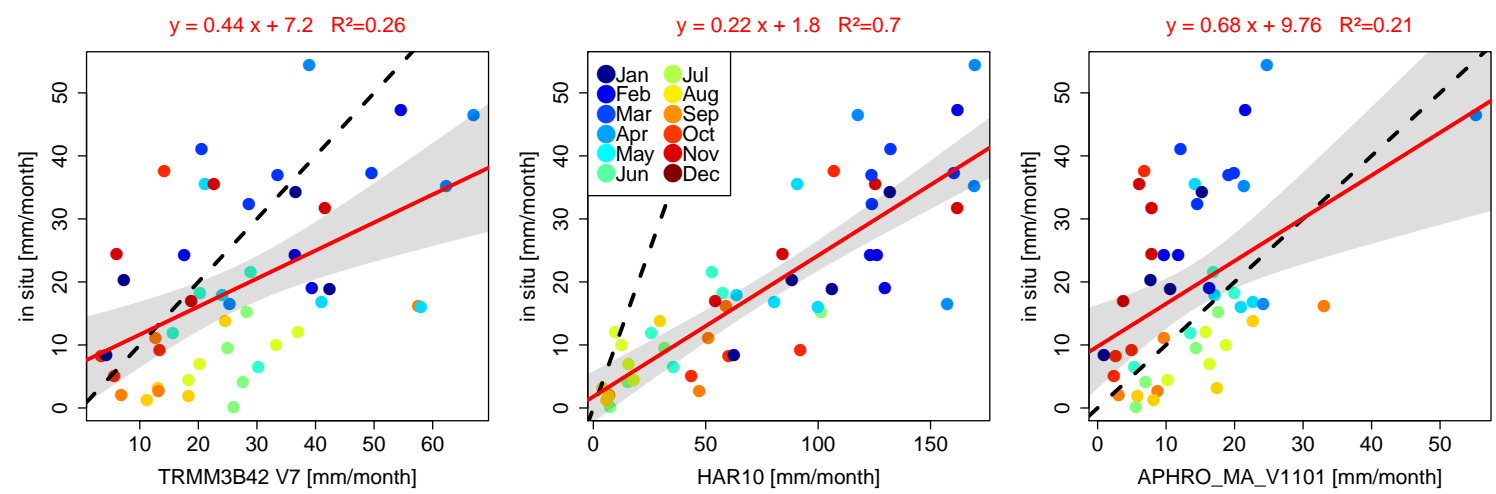

Figure 5. Comparison of precipitation data sets with in situ data on a monthly scale. Colour code for months indicates systematic under- and overestimations for TRMM3B42 V7 and APHRO_MA_V1101. The grey-shaded area marks 95\% modelled confidence interval. TRMM3B42 V7 and APHRO_MA_V1101 show the largest scatter. APHRO_MA_V1101 shows a large negative bias in winter and positive bias in summer. HAR10 has the highest correlation coefficient, but it has a major bias.

Table 3. Precipitation data sets with applied correction factors (CF). APHRO is APHRO_MA_V1101, and TRMM is TRMM3B42 V7. Values inside parentheses correspond to the resulting average annual precipitation amount that an individual data set provides after the application of the correction factor.

\begin{tabular}{lcc}
\hline Data set name & $\begin{array}{c}\text { Correction } \\
\text { factor }(\mathrm{CF})\end{array}$ & $\begin{array}{c}\text { CF for downscaled } \\
\text { HAR10 }\left(\mathrm{CF}^{*}\right)\end{array}$ \\
\hline APHRO $(152 \mathrm{~mm})$ & 1.00 & - \\
APHRO $(200 \mathrm{~mm})$ & 1.30 & - \\
TRMM $(308 \mathrm{~mm})$ & 1.00 & - \\
TRMM $(400 \mathrm{~mm})$ & 1.30 & - \\
HAR10 $(172 \mathrm{~mm})^{*}$ & 0.25 & 1.00 \\
HAR10 $(224 \mathrm{~mm})^{*}$ & 0.32 & 1.30 \\
HAR10 $(258 \mathrm{~mm})^{*}$ & 0.37 & 1.50 \\
\hline
\end{tabular}

* Note that HAR10 in its original version provides $688 \mathrm{~mm}$ of average annual precipitation and has been downscaled in a first step to yield a ratio of unity with in situ measurements. This was done based on the mean of all meteorological stations and the mean of all pixels encompassing these stations (the resulting data set is HAR10 $(172 \mathrm{~mm})$ ). The correction factors stated for HAR10 data sets in the third column were applied after this correction. Resulting overall CFs for HAR10 based on the uncorrected data set are according to $\mathrm{CF}=\mathrm{CF}^{*} / 4.05$. (see Fig. $6 \mathrm{~b}$ and Sect. 4.2 .1 for an explanation).

several reasons. The most important one is to test the sensitivity of the models to precipitation. Second, the comparison of point measurements (in situ data) with gridded data sets (area-integrated values) is biased (Tustison et al., 2001). Third, we have no possibility to assess local precipitation lapse rates (different to the west-east gradient) or methods to infer orographic shielding that could, for example, result in a wet windward and a dry leeward region. Depending on the location of a meteorological station, this can already result in a significant bias between gridded and in situ data. Lastly, there are no validation data for glacier melt. This results in two unknowns - real precipitation amount and real glacier melt contribution to $Q_{\text {tot }}$. Hence, overestimation (underesti- mation) of either quantity can be compensated for by underestimation (overestimation) of the other. Therefore, the evaluation of applied correction factors will be discussed based on the modelled representation of the hydrograph during the snowmelt and glacier melt period, and based on an intercomparison of obtained model results with different forcing data sets.

The TRMM (Tropical Rainfall Measuring Mission) Multi-satellite Precipitation Analysis (TMPA) product TRMM3B42 V7 (Huffman, 1997; Huffman et al., 1997, 2007) was chosen as the remote sensing product due to its frequent use along the Himalayan front (Bookhagen and Burbank, 2010; Roe, 2005; Kamal-Heikman et al., 2007). The 3B42 algorithm uses a two-step approach to compute precipitation distribution. In the first step, TRMM's Visible and Infrared Scanner (VIRS), TRMM Microwave Imager (TMI) orbit data, and TMI/TRMM Combined Instrument (TCI) calibration parameters produce monthly infrared (IR) calibration parameters. In the second step, these calibration parameters are then used to adjust merged-IR precipitation data of several geostationary satellites to derive 3-hourly and daily (derived from the 3-hourly) accumulated precipitation data at $0.25^{\circ} \times 0.25^{\circ}$ spatial resolution with full longitudinal coverage. The data are validated with selected ground-truth information. The newest version (V7) includes additional sources of passive microwave satellite precipitation over the previous version (V6).

Bookhagen and Burbank (2010) assessed TRMM3B42 V6 data to model discharge in the northern Himalayas in the Indus catchment and found good agreement between precipitation intensity and discharge. Roe (2005) reports agreement of TRMM with precipitation gauge measurements in the Himalayas. In comparison to the Himalayas, the Tajik Pamirs only receive little precipitation. As Prigent (2010) points out, the detection of light rain rates and quantification of falling snow is in focus for improvement of accuracy. This problem 
is of special interest for the study area because low precipitation amounts are recorded at the two highest stations, and because low temperatures suggest most of the precipitation to fall as snow. Detection problems of falling snow related to already existent snow cover have been pointed out by, for example, Yin (2004). Even though microwave imagers as used for the TRMM3B42 product can recognise snowfall, the quality relies on the discrimination between frozen precipitation and antecedent snow cover (Skofronick-Jackson and Weinman, 2004). Other authors have reported an underestimation of precipitation in cases of intense snowfall in the Himalayas (Kamal-Heikman et al., 2007). Our analysis of TRMM3B42 V7 data shows data records in winter, when precipitation must fall as snow. These data records show single precipitation events rather than a constant signal that could be expected if the signal was the result of the snow cover (which is persistent throughout the winter). We simply cannot assess the accuracy of TRMM3B42 V7 intensities at this point, but we chose this product to have a remotely sensed product for our approach. To assess its quality performance, we independently applied an interpolated and a climate model data set for validation.

The interpolated data set is the APHRODITE (Asian Precipitation Highly Resolved Observational Data Integration Towards Evaluation of Water Resources) monsoon Asia version 11, APHRO_MA_V1101 (Yatagai et al., 2009, 2012). The monsoon Asia region with a spatial coverage of $15^{\circ} \mathrm{S}-$ $55^{\circ} \mathrm{N}$ and $60-155^{\circ} \mathrm{E}$ and a temporal coverage from 1951 to 2007 with daily temporal resolution was used. The product is a weighted interpolation product of ground-based precipitation gauge data. The weighting is based on horizontal distance and an orographic correction model. Andermann et al. (2011) demonstrated that APHRODITE monsoon Asia V1003R1 is the best-performing precipitation data set available for the central Himalayas, and the successor data set, APHRO_MA_V1101, has also been applied for Himalayanwide glacier melt studies (Lutz et al., 2014).

The third data set is that of the High Asia Reanalysis (Maussion et al., 2014). The data result from a dynamical downscaling of global analysis data (Final Analysis data from the Global Forecasting System (National Centers for Environmental Prediction, NOAA, US Department of Commerce, 2000; data set ds083.2) using the Weather Research and Forecasting (WRF-ARW) model (Skamarock and Klemp, 2008). Hence the quality of HAR depends on the global analysis data used as initialisation, as well as the model's capability to simulate the atmospheric processes. Maussion et al. (2011) have shown good correlation of HAR with rain gauge data despite occasional overestimation on the Tibetan Plateau. Hence, HAR is assumed to show a good representation of seasonal patterns, however with the limitation of the need to calibrate precipitation intensities. From the different spatial resolutions available (30 and $10 \mathrm{~km})$, we use the $10 \mathrm{~km}$ version (HAR10) for precipitation without making use of the discriminated rain/snow parts, as we leave this to be the subject of the model optimisation. Mölg et al. (2013) show that HAR10 shows good agreement with automatic weather stations on the Tibetan Plateau and therefore has high potential for glacier studies.

Comparison of each data set with in situ data shows that differences in monthly added-up values for TRMM3B42 V7 and APHRO_MA_V1101 are relatively small compared to HAR10 (Fig. 6a). Seasonal biases are, however, very pronounced for all data sets. HAR10 shows high overestimations in winter. The ratio of an individual data set and in situ data (Fig. 6b) reveals that HAR10, despite overestimating, shows a constant ratio to in situ data, suggesting a rather systematical error.

It should be noted that the obtained ratio is strongly biased by the included meteorological stations used in this comparison. Figure $6 \mathrm{~b}$ shows, for example, that the individual resulting ratios of HAR10 with the two sites Navabad and Bulunkul differ by a factor of 3.5. As mentioned in Sect. 2, station Bulunkul is surrounded by mountain flanks that likely intercept incoming precipitation. This might lead to the pronounced overestimation of HAR10 in this situation.

APHRO_MA_V1101 and TRMM3B42 V7 show varying ratios but a lesser volume mismatch. If assuming positive precipitation lapse rates a grid value of either data set should overestimate observational data, because meteorological stations are located on the valley floors. However, HAR10 precipitation in its original version provided too much precipitation to the model, being unable to deal with resulting extremely high snowmelt amounts. Based on that we correct HAR10 precipitation intensities downward to obtain a ratio with in situ data of 1 . This downward correction at the beginning is only conducted for HAR10 because the other data sets were able to simulate the hydrograph. In a second step we apply correction factors to all precipitation data sets to account for possible positive precipitation lapse rates. We apply factors ranging from 1 to 1.5 (see Table 3 ) to the individual precipitation data sets. In the case of the downscaled HAR10 data set, the resulting overall factor with respect to the original data ranges from 0.25 to 0.37 . Hereafter, we refer to the data sets according to their annual average precipitation amount, e.g. HAR10 $(172 \mathrm{~mm})$ for the HAR10 version with $172 \mathrm{~mm}$ average annual precipitation.

The precipitation data sets show different spatial and seasonal distributions. TRMM3B42 V7 and APHRO_MA_V1101 both show a similar seasonal distribution (Fig. 10), whereas HAR10 has $\approx 20 \%$ more precipitation in winter and spring combined. Only $8 \%$ of HAR10's annual precipitation is provided in summer, compared to $23 \%$ for TRMM3B42 V7 and APHRO_MA_V1101. Compared to the average annual discharge volume of $3.48 \mathrm{~km}^{3} \mathrm{yr}^{-1}$ (i.e. $255 \mathrm{~mm} \mathrm{yr}^{-1}$ ), only TRMM $(308 \mathrm{~mm}$ ) (i.e $\left.4.2 \mathrm{~km}^{3}\right)$ and the original HAR10 data set $(688 \mathrm{~mm})$ (i.e. $9.38 \mathrm{~km}^{3}$ ) provide more precipitation. 

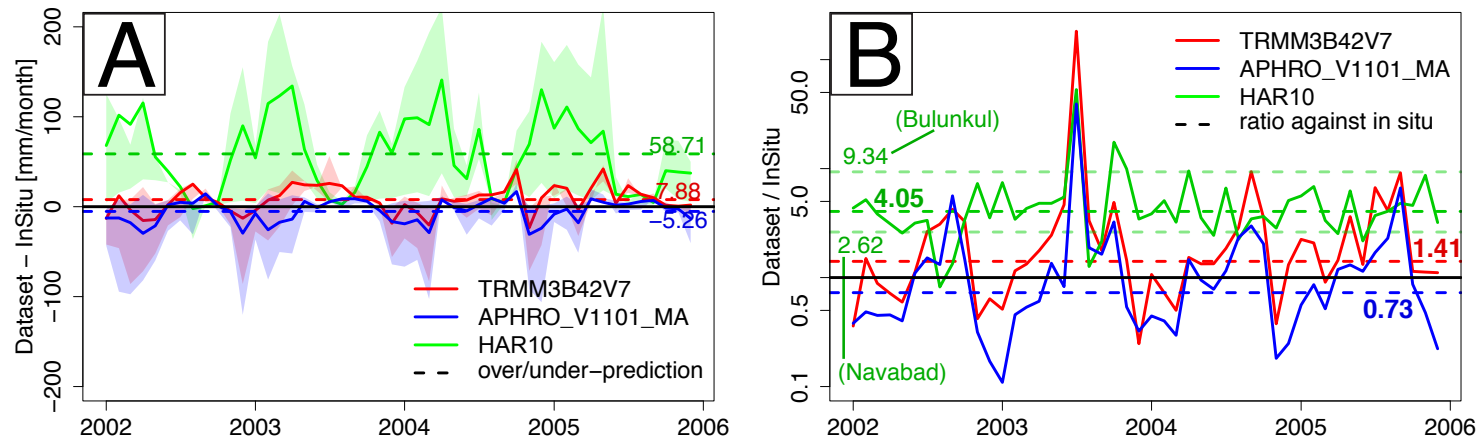

Figure 6. Comparison of precipitation data sets with in situ data. Solid lines are mean monthly values for all pixels encompassing meteorological stations. Dashed horizontal lines are mean values for the entire period from 2002 to 2006. (a) Difference in intensities on a monthly basis. There is strong overestimation for HAR10 and underestimation for TRMM3B42 V7 and APHRO_MA_V1101 in winter. Shaded area marks range between minimum and maximum of raster and in situ data. (b) Normalised data sets by in situ data show a constant value of $\approx 4$ for HAR10 and varying values for TRMM3B42 V7, and APHRO_MA_V1101 (extreme values in summer 2003 due to almost no recorded precipitation events in the in situ data set). Ratios of individual sites to a data set pixel encompassing this site can vary substantially (compare Navabad and Bulunkul). Different correction factors are applied to account for this uncertainty (see Sect. 4.2.1). Note the logarithmic scale.
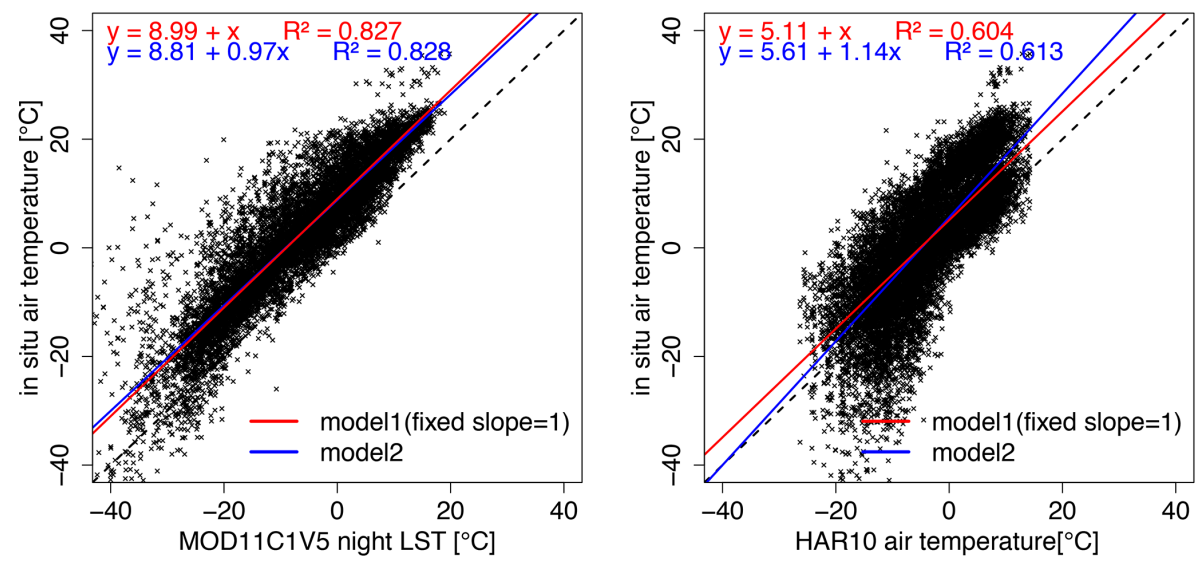

Figure 7. Comparison of MODIS MOD11C1 V5 night LST and HAR10 $2 \mathrm{~m}$ air temperature with in situ data. Scatter plots represent values for all pixels encompassing a meteorological station providing data. Scattering is actually smaller and correlation is higher when comparison is based on a single pixel and the encompassed meteorological station data. For calibration, the intercept values of the linear models with fixed slope of 1 (red) are added to the original data sets.

\subsubsection{Temperature}

We use two different data sets for air temperature - one derived from remote sensing data and one from a climate model data set. The data sets are calibrated based on available in situ data. Remote sensing determination of air temperature at ground level is not available at a global scale. Land surface temperatures (LSTs), on the other hand, can be determined from surface-emitted thermal infrared radiation, which can pass through the atmosphere. It can thus be measured with appropriate instruments from space. We correlate LSTs with in situ data to use them as a proxy for air temperatures.

The LST data set is the MODIS MOD11C1 V5 (Wan and Li, 1997; Wan et al., 2004; Wan, 2008) data that provide night and daytime LST along with emissivity. The data are available as a $0.05^{\circ} \times 0.05^{\circ}$ resolution climate modelling grid (CMG) in daily temporal resolution. The determination of the LST is based on the thermal infrared (TIR) radiation emitted by the surface in combination with the emissivity of the surface material. Information from other MODIS products, e.g. land cover (MOD12), snow cover (MOD10), and cloud mask (MOD35), is incorporated in the algorithms (Wan, 2008). We chose the MOD11C1 V5 data set over the MOD11C1 V4 one due to better spatial coverage and improvements for high altitude (Wan, 2008). Missing values that occur mainly due to cloud cover, or missing files in the data set, were temporally interpolated using smoothing splines from R's stats package (R Core Team, 2014). The method was applied to each grid cell/pixel. Applicability of using LST as a proxy for air temperature has been demonstrated, for example, by Kawashima et al. (2000), Mostovoy et al. (2006), and Deus et al. (2013). 
The climate model data set is the HAR10 $2 \mathrm{~m}$ air temperature data. It is based on the same downscaling method used for HAR10 precipitation that was mentioned before. Due to HAR10's reported usefulness for glacier balance studies (Mölg et al., 2013) and good representation of snow cover on the Tibetan Plateau (Maussion et al., 2011), along with a distinct correlation with in situ data (Fig. 7), we include this data set to see whether it provides a good all-in-one solution for the two key meteorological drivers. Correlation with in situ temperatures is expectedly lower compared to MODIS MOD11C1 V5, because of HAR10's coarser spatial resolution of $10 \mathrm{~km}$, which averages values over a larger spatial domain.

Our comparison of LST with in situ air temperature shows high correlation $\left(R^{2}=0.83\right.$ for all pixels encompassing meteorological stations) (Fig. 7). Pronounced underestimation for lower temperatures reduces the overall slope. This leads to an increased underestimation for higher temperatures. Therefore, we apply a linear regression with a fixed slope of one (linear model 1) to have a more representative dependency for the more important higher temperatures (affecting freezing, melting, and evapotranspiration). Based on the regression analysis, we calibrate the LST data set to match the observed air temperatures from the meteorological stations. Comparison of HAR10 and in situ data show a similar characteristic, and hence we apply the same correction procedure.

\subsubsection{Wind speed and relative humidity}

Wind speed and relative humidity data are based on the Noah land surface model (Chen and Dudhia, 2001; Chen et al., 2007; Ek et al., 2003) from the Global Land Data Assimilation System (GLDAS) (Rodell et al., 2004). We use the GLDAS_NOAH025SUBP_3H (Hydrological Sciences Branch at NASA/Goddard Space Flight Center , GSFC/HSB) data set provided in 3-hourly temporal and $0.25^{\circ} \times 0.25^{\circ}$ spatial resolution. The data basis comprises various satellite and in situ data (for more information see http://mirador.gsfc.nasa.gov/collections/GLDAS_ NOAH025SUBP_3H_001.shtml).

The extracted 3-hourly wind speed data were averaged to daily data. For relative humidity, further calculations had to be performed as GLDAS_NOAH025SUBP_3H only provides specific humidity. Water vapour and atmospheric pressures are needed to calculate relative humidity from specific humidity (Häckel, 1999). However, GLDAS_NOAH025SUBP_3H does not provide vapour pressure. Therefore, relative humidity was calculated based on information provided by the LP DAAC (Land Processes Distributed Active Archive Center) (see Appendix A).

\subsubsection{Sunshine duration}

For sunshine duration, coarse $\left(0.75^{\circ} \times 0.75^{\circ}\right)$ ECMWF $(\mathrm{Eu}-$ ropean Centre for Medium-Range Weather Forecast) ERA-
Interim data were obtained from ECMWF servers. ERAInterim data incorporate modelled climate data from a wide range of satellite and in situ measurements (Dee et al., 2011). Sunshine duration is demanded by the model internal calculation of global radiation. It serves as a proxy for cloudiness to reduce the internally calculated extraterrestrial radiation.

\section{Model calibration}

The JAMS framework utilises the Shuffled Complex Evolution method of the University of Arizona (SCE-UA) (Duan et al., 1994), which is efficiently approaching an optimal set of model calibration parameters in an iterative process (Fischer et al., 2009). A set of given values for the calibration parameters will result in a certain realisation of a chosen efficiency criterion. All possible realisations will span a surface in a $n+1$ dimensional space, where $n$ is the number of calibration parameters. The SCE-UA algorithm searches for the optimal calibration that is given by the global maximum or minimum (depending on whether the efficiency criterion has to be maximised or minimised) of this surface. The term "shuffled complex" derives from multiple sets of points (complexes) that are used to approach the extrema. The points that belong to a complex are shuffled every iteration (evolution), enabling the algorithm to search the surface in a very efficient way, as has been shown by Duan et al. (1994). The Nash-Sutcliffe efficiency (NSE) (Nash and Sutcliffe, 1970) was chosen as the efficiency criterion.

The NSE calculation is based on modelled and measured daily discharge measurements for Khorog (see Sect. 2). The same SCE optimisation procedure is conducted for all model setups. We always add an additional $300 \mathrm{~mm}$ to a each precipitation data set at the beginning of the modelling period to account for empty groundwater storages and snow stocks. For the earlier-starting setups with temperature from MOD11C1 V5 this is on 1 March 2000, and for the setups with HAR10 temperature it is on 1 January 2001. The spinup phase ends on 1 January 2002. Similar baseflow and snow stock values for the models with different temperature data suggest sufficient spin-up time for the setups with HAR10 that only have a 1-year spin-up phase. The actual calibration is then restricted to the period from 2002 to 2007. Due to the short period of available in situ data and high interannual variability in observed discharge, we use all available data for calibration and do not carry out an additional validation period. Instead, we address observed differences of individual modelled years to point out differences in forcing data and their effect on the hydrological cycle.

\section{Results}

The majority of the optimised models were consistent in their representation of the hydrological cycle and required similar calibration parameters. All models agreed on a substantial 

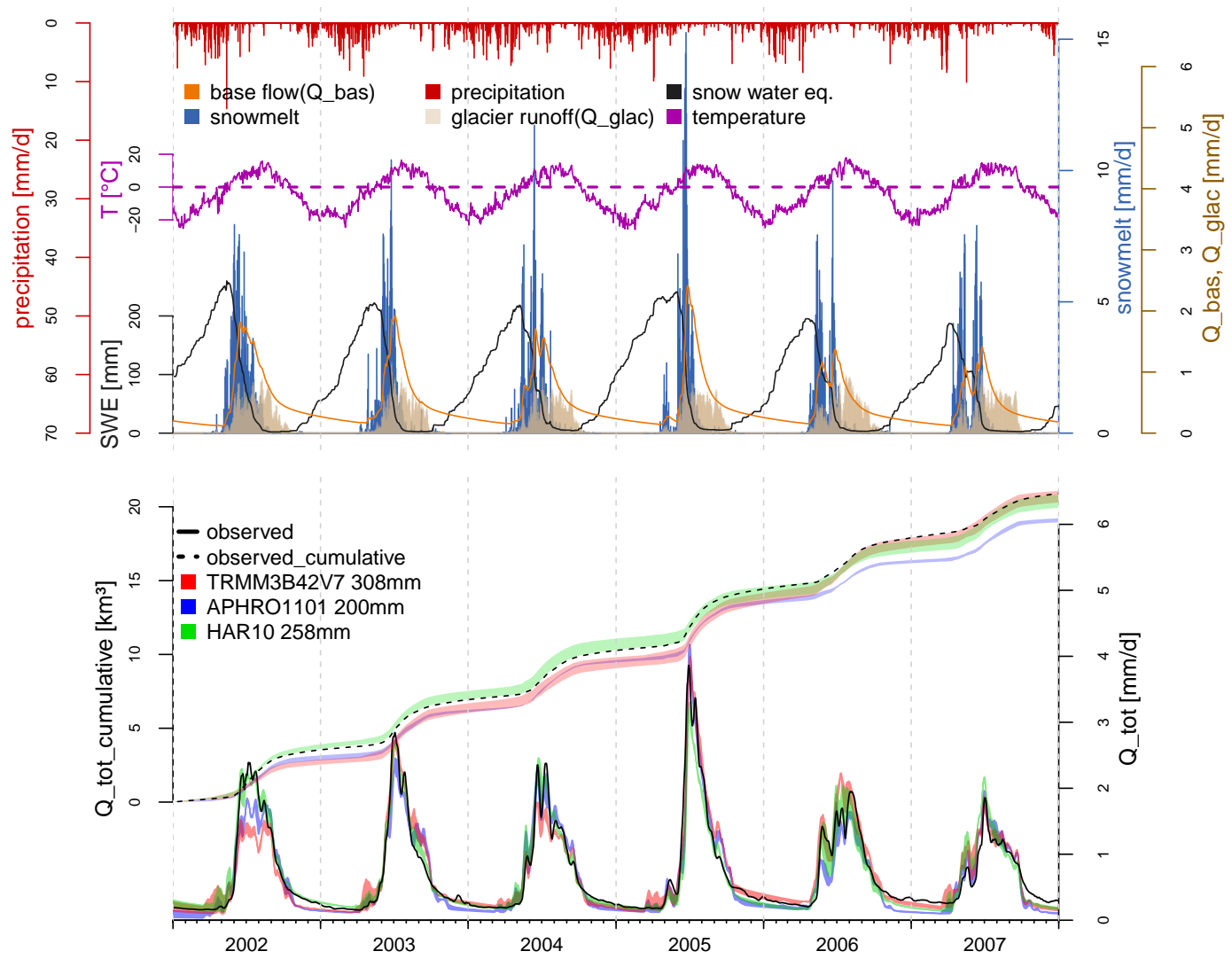

Figure 8. J2000g modelling results. Upper panel shows the individual water components for the overall best-performing model setup with MOD11C1 V5 temperature and HAR10 $(258 \mathrm{~mm})$. Note different scaling for $Q_{\text {bas }} / Q_{\text {glac }}$ compared to snowmelt, due to higher magnitude of snowmelt. Lower panel shows observed and modelled hydrographs and cumulative hydrographs. Displayed range (shaded area) corresponds to different temperature data sets.

amount of groundwater discharge and a transition from snow into glacier melt during summer. Strongest differences were apparent if significantly different amounts of winter precipitation were provided. The fact that cold temperatures during winter prevented any liquid precipitation and snow or glacier melt caused a strong constraint on the parameterisation of the groundwater aquifer. Low winter precipitation resulted in increased glacier melt and vice versa. Modelled variabilities in the well-pronounced intra-annual cycle were consistent between different models and independent of the precipitation data set used. This highlights the temporal decoupling of precipitation and discharge, and a strong influence of temperature on the modelling.

\subsection{Modelling results}

Best NSE and lowest RMSE (root-mean-squared error) were obtained using a combination of MOD11C1 V5 temperature and HAR10 $(258 \mathrm{~mm})$ precipitation (Table 1). Setups with MOD11C1 V5 temperature consistently resulted in better NSE and 7-15\% smaller RMSE than setups with HAR10 temperature. The hydrological cycle according to the best obtained model results is shown in Figs. 8 and 9 and can be summarised as follows: starting at the end of autumn, all precipitation is accumulated as snow cover. During this time $Q_{\text {tot }}$ results entirely from $Q_{\text {bas. }}$. In April, the melting season starts with high peak discharges and replenishment of the groundwater reservoir. Snow stocks rapidly decline between April and July (Fig. 9a). During the middle of the melting season (July, August) snowmelt transitions into glacier melt. Finally, at the end of summer, there is no snow cover left and glacier melt is the only meltwater component. At this time, $Q_{\text {tot }}$ consists mainly of groundwater discharge and, to a lesser extent, glacier melt (Fig. 9b). Then the cycle starts again. Because glacier melt directly becomes $Q_{\text {dir }}$ in the model, it cannot infiltrate into soils and storage components. As a result, only snowmelt and rainfall contribute to groundwater replenishment. Glacier melt is the only effective surface runoff component during late summer. actET correlates with snowmelt and shows highest values in the narrow period from May to July, peaking in June with values of $1 \mathrm{~mm} \mathrm{day}^{-1}$ (Fig. 9a). Before temperature peaks in August, snow stocks are diminished, causing only glacier melt to correspond to the temporal progression of temperature. 

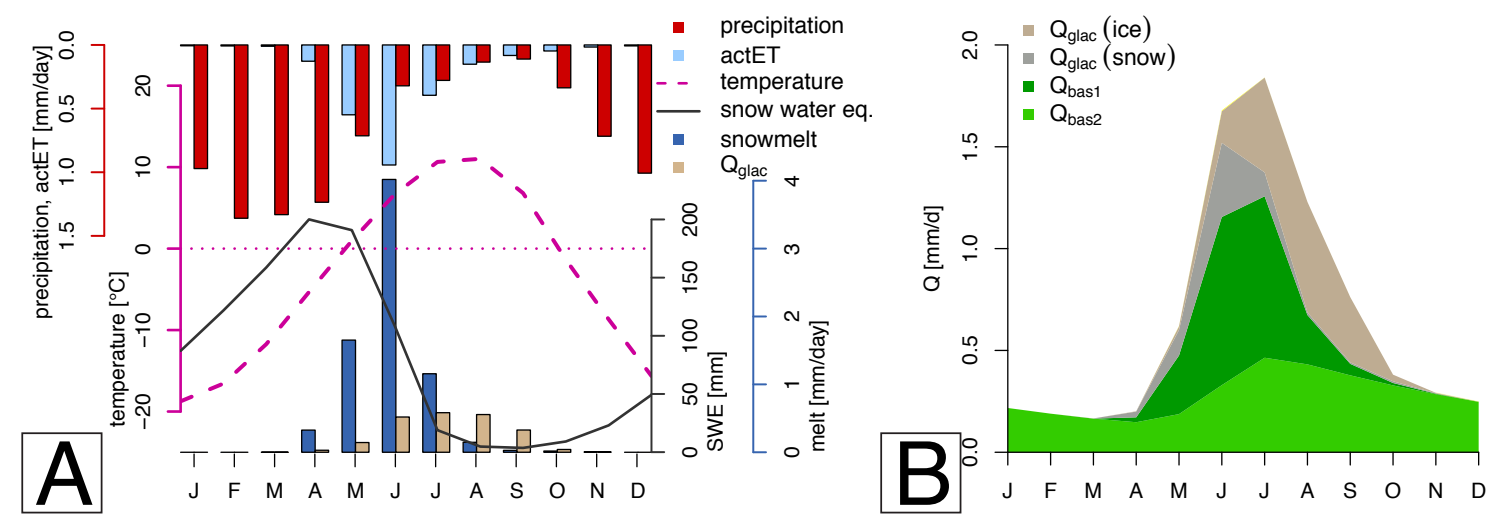

Figure 9. Monthly average hydrometeorological components (a) and hydrograph with discharge components (b) based on modelling results from 2002 to 2007 for the best-performing setup with HAR10 $(258 \mathrm{~mm})$ precipitation and MOD11C1 V5 temperature.
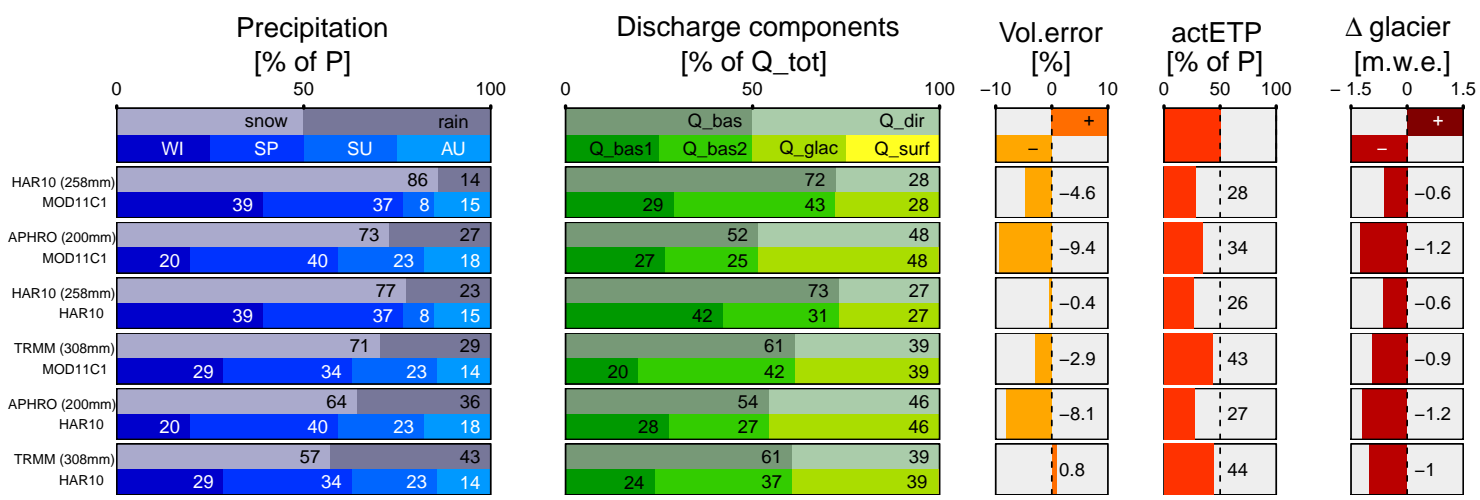

Figure 10. Average annual/intra-annual model results for the two different temperature data sets in combination with the individual bestperforming precipitation data set. Descending ordering according to best NSE. The first panel is the legend. All discharge components as percent of average annual $Q_{\text {tot }}$. Negligible amounts of $Q_{\text {surf }}$ result from the model's treatment of snowmelt water with a recession, which is therefore represented by $Q_{\text {bas1 }}$ (see Sect. 3.2).

Smallest deviations for cumulative discharge were observed for models with precipitation from HAR10 $(258 \mathrm{~mm})$. For setups with TRMM $(308 \mathrm{~mm})$, a higher underestimation in 2002 and 2004, when SWE values were also much smaller, compared to HAR10 $(258 \mathrm{~mm})$ and APHRO $(200 \mathrm{~mm})$ was observed. Use of APHRO $(200 \mathrm{~mm})$ resulted in the highest underestimation, which is most pronounced in winter. Higher glacier melt in summer for setups with APHRODITE_MA_V1101 precipitation reduced this underestimation in summer. The higher fraction of summer precipitation for TRMM3B42 V7 and APHRODITE_MA_V1101 was accompanied by a higher contribution of glacier runoff to total discharge and more negative glacier mass balances (Fig. 10). All models showed highest deviations from observed discharge in 2006 and 2007, which might be related to the mentioned lake level regulations. We could not verify this assumption.

Comparison of the best individual model setups regarding their inputs and outputs is presented in Fig. 10. The best models showed a higher fraction of snowfall over rainfall. A par- ticular precipitation data set showed higher snowfall proportions $(\approx 10 \%)$ with MOD11C1 V5 temperatures compared to HAR10 temperatures. Despite the big differences in snow fraction, values for $Q_{\text {bas } 1}$ (resulting from snowmelt) showed comparable results of $\approx 20-30 \%$ of $Q_{\text {tot }}$. An exception was the model using the combination of HAR 10 temperature and HAR10 $(258 \mathrm{~mm})$ precipitation with $42 \% Q_{\text {bas } 1}$. This was accompanied with the longest recession coefficient for the fast recession subsurface flow (GWK1) of $\approx 38$ days. Other models with HAR10 temperature show values for GWK1 between 14 and 30 days and models with MODIS temperature show values between 10 and 19 days (Table 4). Despite this deviation, and despite the difference between the proportions of $Q_{\text {bas1 }}$ to $Q_{\text {bas2 }}$ for either temperature data set, all models showed high consistency for (1) the sum of $Q_{\text {bas1 }}$ and $Q_{\text {bas2 } 2 \text {, }}$ (2) the ratio of $Q_{\text {bas }}$ over $Q_{\text {dir }}$, (3) the proportion of $Q_{\text {glac }}$ to $Q_{\text {tot }}$, and (4) the glacier mass balances. Only actET and the volume errors showed noticeable differences.

The groundwater proportion in the hydrological cycle ( $\left.Q_{\text {bas } 2}\right)$ made up $\approx 40 \%$ of $Q_{\text {tot }}$ with the exceptions of the 
Table 4. Model parameterisations and NSE for the calibration time period 2002 to 2007.

\begin{tabular}{|c|c|c|c|c|c|c|c|c|c|c|c|c|c|c|}
\hline Model setup & $\mathrm{T}_{\text {base }}$ & $\mathrm{TMF}_{\mathrm{s}}$ & $\mathrm{T}_{\text {base }_{\mathrm{g}}}$ & $\mathrm{TMF}_{\mathrm{gs}}$ & $\mathrm{TMF}_{\mathrm{gi}}$ & ETR & $\operatorname{maxPerc}$ & LVD & FCA & gwStorAlpha & $\mathrm{GWK}_{1}$ & $\mathrm{GWK}_{2}$ & RMSE & NSE \\
\hline \multicolumn{15}{|c|}{ MODIS MOD11C1 V5 temperature } \\
\hline APHRO $(154 \mathrm{~mm})$ & 6.08 & 3.77 & -4.49 & 3.87 & 1.05 & 0.44 & 10.37 & $4.18 \times 10^{-2}$ & $4.07 \times 10^{-3}$ & 0.72 & 12.59 & 339.07 & 41.05 & 0.86 \\
\hline APHRO $(200 \mathrm{~mm})$ & 7.16 & 6.47 & -4.29 & 3.07 & 0.86 & 0.45 & 5.02 & $1.69 \times 10^{-2}$ & $2.28 \times 10^{-2}$ & 0.55 & 12.50 & 393.88 & 36.58 & 0.89 \\
\hline HAR10 (172 mm) & 6.15 & 3.86 & -3.15 & 1.48 & 1.04 & 0.48 & 9.36 & $2.46 \times 10^{-2}$ & $3.56 \times 10^{-3}$ & 0.59 & 14.47 & 242.89 & 38.29 & 0.88 \\
\hline HAR10 (224 mm) & 5.33 & 3.51 & -0.04 & 3.45 & 1.18 & 0.24 & 8.35 & $3.19 \times 10^{-3}$ & $4.55 \times 10^{-3}$ & 0.44 & 14.66 & 353.85 & 33.97 & 0.90 \\
\hline HAR10 (258 mm) & 5.01 & 4.31 & 0.96 & 4.07 & 0.89 & 0.45 & 12.08 & $1.26 \times 10^{-3}$ & $3.56 \times 10^{-2}$ & 0.41 & 19.16 & 216.49 & 32.47 & 0.91 \\
\hline TRMM (308 mm) & 4.00 & 2.63 & -0.89 & 3.76 & 1.02 & 0.32 & 7.60 & $2.19 \times 10^{-3}$ & $1.26 \times 10^{-1}$ & 0.34 & 10.35 & 287.54 & 38.80 & 0.87 \\
\hline TRMM (400 mm) & 2.65 & 5.10 & 1.22 & 1.91 & 1.25 & 0.65 & 8.10 & $2.07 \times 10^{-2}$ & $6.01 \times 10^{-1}$ & 0.32 & 15.84 & 393.98 & 40.26 & 0.86 \\
\hline \multicolumn{15}{|l|}{ HAR10 temperature } \\
\hline APHRO (154 mm) & 3.82 & 2.49 & -4.86 & 1.29 & 0.94 & 0.14 & 14.41 & $2.73 \times 10^{-1}$ & $1.97 \times 10^{-2}$ & 0.69 & 14.32 & 288.64 & 45.00 & 0.83 \\
\hline APHRO $(200 \mathrm{~mm})$ & 2.57 & 4.85 & 0.55 & 3.40 & 1.19 & 0.35 & 12.90 & $2.54 \times 10^{-3}$ & $1.40 \times 10^{-4}$ & 0.50 & 20.55 & 355.71 & 41.50 & 0.86 \\
\hline HAR10 (172 mm) & 3.76 & 6.95 & 0.18 & 2.02 & 1.11 & 0.35 & 11.03 & $2.62 \times 10^{-3}$ & $4.37 \times 10^{-4}$ & 0.53 & 21.02 & 395.76 & 41.04 & 0.86 \\
\hline HAR10 (224 mm) & 3.46 & 7.85 & 1.34 & 2.80 & 0.91 & 0.66 & 11.64 & $1.23 \times 10^{-3}$ & $4.95 \times 10^{-2}$ & 0.54 & 30.29 & 399.34 & 38.25 & 0.88 \\
\hline HAR10 (258 mm) & 3.17 & 7.08 & 2.03 & 3.74 & 0.72 & 0.21 & 2.96 & $7.96 \times 10^{-4}$ & $9.24 \times 10^{-2}$ & 0.60 & 38.61 & 398.98 & 37.57 & 0.88 \\
\hline TRMM (308 mm) & 0.45 & 5.20 & 0.23 & 1.08 & 1.11 & 0.01 & 10.30 & $1.99 \times 10^{-2}$ & $1.17 \times 10^{-1}$ & 0.42 & 22.53 & 263.04 & 42.91 & 0.85 \\
\hline TRMM (400 mm) & -0.78 & 4.97 & 0.70 & 1.52 & 1.21 & 0.29 & 10.25 & $1.75 \times 10^{-3}$ & $5.08 \times 10^{-1}$ & 0.39 & 22.27 & 388.09 & 43.80 & 0.84 \\
\hline
\end{tabular}

model setups using only HAR10 data and the models using APHRO (200 mm) (Fig. 10). Glacier mass balances show a factor of 2 difference. Smallest losses of $-0.6 \mathrm{~m}$ w.e. $\mathrm{yr}^{-1}$ were obtained with HAR10 $(258 \mathrm{~mm})$. Highest losses of $-1.2 \mathrm{mw}$.e. $\mathrm{yr}^{-1}$ were obtained with APHRO $(200 \mathrm{~mm})$, which also showed the strongest negative volume errors of $\approx-9 \%$ and substantially higher $Q_{\text {glac }}$. Since this indicates a strong underestimation of the already upwardcorrected APHRO $(200 \mathrm{~mm})$ data set, we do not think that obtained model results of APHRO $(200 \mathrm{~mm})$ are representative of the hydrological cycle. $Q_{\text {glac }}$ makes up $\approx 30 \%$ of annual $Q_{\text {tot }}$ with HAR10 $(258 \mathrm{~mm})$ and up to $40 \%$ with TRMM $(308 \mathrm{~mm})$. The apparent higher glacier contribution for TRMM $(308 \mathrm{~mm})$ - despite providing more annual precipitation - is compensated for by increased actET and is due to a higher portion of summer precipitation compared to HAR10 (258 mm).

\subsection{Sensitivity analysis}

Our sensitivity analysis is based on the convergence or nonconvergence of calibration parameters and their value range obtained with the SCE-UA method with NSE as the optimisation criterion. Three groups of parameters can generally be differentiated. These groups are the ones determining (1) snowmelt, (2) glacier melt, and (3) groundwater properties. At the beginning of the hydrological cycle, the snowmelt parameters dominate the representation of the hydrograph because snowmelt is the main contributor to river discharge. Then, depending on how much snow remains, glacier melt will start. Lastly, depending on when and how much water is available by means of snowmelt, respective groundwater parameters have to ensure that the water release is correctly retarded and adjusted. The total amount of precipitation amassed as snow during the winter will thus represent the most important factor for the parameterisation.
We used a set of 12 calibration parameters (Table 1) and 8 complexes in the SCE-UA optimisation. Parameter values converged after 4000-5000 runs and showed no more than $1 \%$ improvement in NSE later on. With limited information about specific soil and aquifer properties, all related soil and groundwater parameters were included in the SCE-UA optimisation process. Wide value ranges for the calibration parameters allowed for possible equifinality. Figure 11 shows the parameter calibration for both temperature data sets independently. The best parameterisation as well as the value ranges for the individual best-performing precipitation data sets is highlighted. When considering all of the applied temperature and precipitation data sets, the most restricted parameters were $\mathrm{TMF}_{\mathrm{gi}}$ and $\mathrm{LVD}$, followed by Tbase, FCA, and Tbase $_{\mathrm{g}}$. The most unrestricted parameters were the groundwater and the fast linear storage-component-related parameters GWK2, gwStorAlpha, maxPerc, and GWK1. In addition to these, TMF and ETR appear to be unrestricted. Constraints for a certain parameter were largely independent of the temperature data set used.

The degree-day factor for glacier melt $\mathrm{TMF}_{\mathrm{gi}}$ always showed a narrow value range of about $1 \mathrm{~mm}^{\circ} \mathrm{C}^{-1} \mathrm{day}^{-1}$. Degree-day factors for snow were less constrained. The most obvious difference regarding the use of a specific temperature data set were observed for the obtained threshold temperatures Tbase. Tbase for models with MOD11C1 V5 was about $2-3{ }^{\circ} \mathrm{C}$ higher than for models with HAR10 temperature. The threshold temperature for glaciers, Tbase $\mathrm{g}$, did not show such a distinction between the different temperature data sets. Low-precipitation-volume data sets, such as APHRO (154 and $200 \mathrm{~mm})$ and HAR10 $(172 \mathrm{~mm})$, led to lowest Tbase $_{\mathrm{g}}$ values in the setups with MOD11C1 V5. No such effect was observed with HAR10 temperature. The field capacity correction factor, FCA, and the discrimination factor, LVD, for lateral or vertical distribution of soil excess water were both very low - i.e. the soil was modelled to 

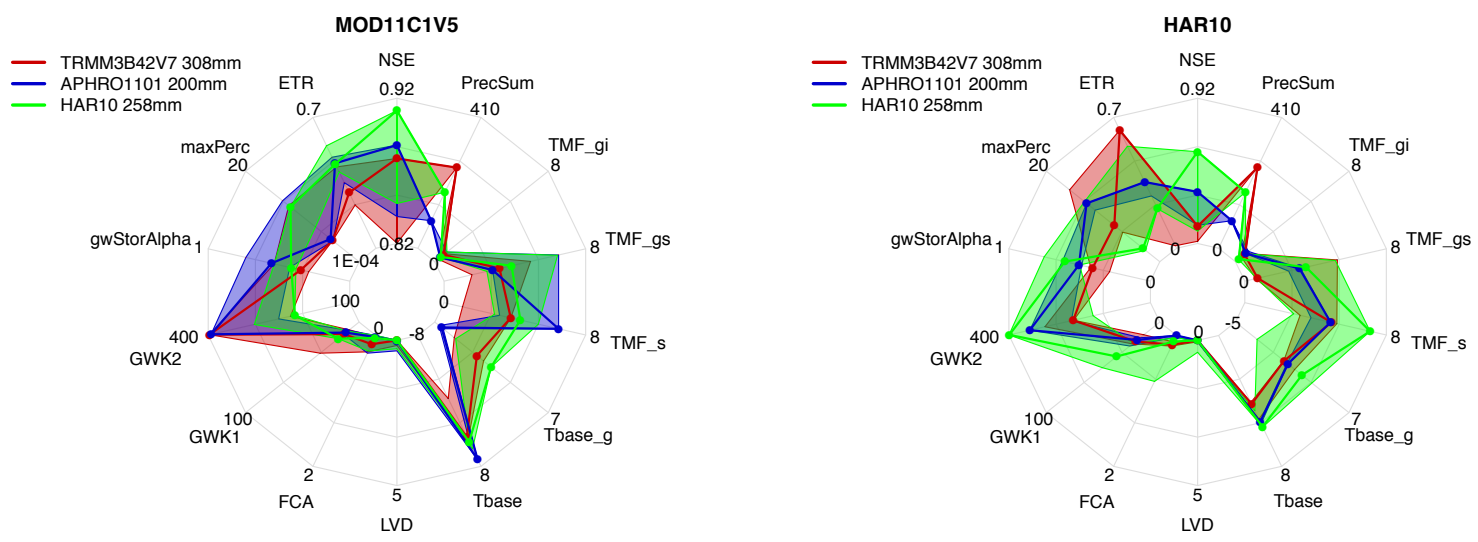

Figure 11. Ranges (shaded areas) for calibration parameters during the last steps of SCE-UA optimisation. Only parameterisations for NSE $\geq 0.82$ are considered. Possible value ranges are according to Table 1 . The left panel displays realisations with setups using MOD11C1 V5 temperatures, and the right panel shows those with HAR10 temperatures. Solid lines represent best-performing individual precipitation data sets. PrecSum is the average annual precipitation.
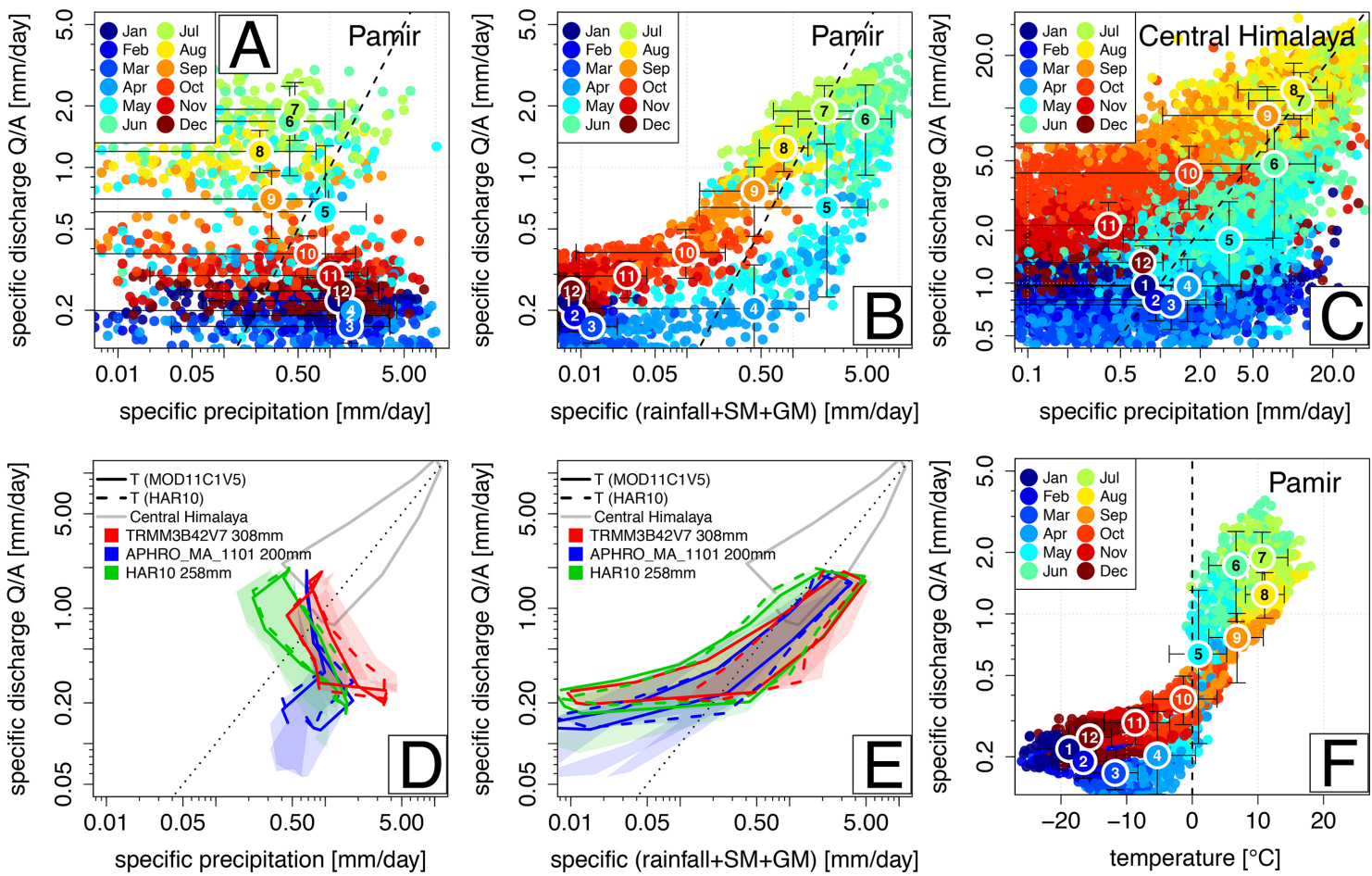

Figure 12. Area-normalised discharge (specific discharge) dependencies on area-normalised precipitation (specific precipitation) and specific effective precipitation $P_{\text {eff }}$, i.e. all liquid water input from rainfall, snowmelt (SM), and glacier melt (GM). All plots except for (f) are on a bi-logarithmic scale. Modelled discharge (MOD11C1 V5 temperature and HAR10 $(258 \mathrm{~mm})$ precipitation) response to (a) precipitation and (b) $P_{\text {eff }}$. Colour-coding corresponds to month of the year. Error bars represent 95 th percentiles and numbers represent mean monthly values. Panels (d) and (e) include model results from all other model combinations (shaded area) showing the same relationships as (a) and (b), respectively; colour coding corresponds to precipitation data sets. Best individual precipitation data sets with either temperature data set are represented by the solid or dashed lines. Panel (c) shows for comparison purposes the discharge-rainfall relationship for the Naryani catchment, central Himalayas, Nepal. The shape is included in (d) and (e) to highlight similarity in shape but different order of magnitude in both discharge and precipitation. Panel (f) displays modelled discharge-temperature relationship.

store very little water and distribute the majority of this water to the underlying storage components. For the setups with
MOD11C1 V5, the resulting values were (1) lower than for setups with HAR10 temperature and (2) more constrained. 


\section{Discussion}

Independent of the used data sets, i.e. whether interpolated, remote sensing, or regional climate model data were used, the models yield comparable and confident results regarding the representation of the hydrological cycle. There is, however, an important dependency of model performance with the amount of precipitation provided during the snow accumulation period in winter. Too high winter precipitation leads to the model failing to produce meaningful results. Low winter precipitation causes overestimated high glacier melts. The lack of in situ measurements does not allow us to determine the thresholds with certitude.

Most striking is the fact that the relationship of precipitation to discharge is expectedly variable for individual precipitation data sets (Fig. 12d), but the relationship of resulting liquid water input (from snow and glacier melt and liquid precipitation) to discharge shows a high consistency (Fig. 12e). This consistency results from the dominant role of temperature as the trigger for meltwater and the overall delay between precipitation and discharge. To account for spring and summer discharge, variable melt is required, thus leading to slightly different model parameterisations to adapt to precipitation input. As the bulk of precipitation is provided as snow, but only released as meltwater in summer, groundwater discharge is essentially the only contributor to river streamflow for the winter half-year. This finding implies fundamental characteristics of expected surface processes due to the quick and concentrated release of surface water, which is gradually released with increasing altitude (Fig. 13). In contrast with the low annual precipitation amount of $<300 \mathrm{~mm} \mathrm{yr}^{-1}$, the rapid release of these water amounts implies a very different response of surface processes to a situation when precipitation was distributed more evenly during the year. Due to the transition from snow into glacier melt, glaciated catchments in the Pamirs are also expected to behave characteristically differently to nonglaciated ones due to a high contribution of glacier melt and the consequent absence of significant amounts of surface water in non-glaciated catchments.

\subsection{Data set characteristics}

Precipitation is the most important but also most problematic meteorological parameter in the Pamirs. None of the three tested data sets should be used without careful analysis in the Pamir region for hydrological or climatological studies. In particular, we find the three data sets to have the following issues. TRMM3B42 V7 most likely suffers from reported issues on snowfall determination (Yin, 2004; Kamal-Heikman et al., 2007; Skofronick-Jackson and Weinman, 2004; Prigent, 2010) that result in, for example, low snow stocks that lead to the underestimation of the hydrograph in 2002 and 2004. The fact that TRMM detects precipitation when there must be at least partial snow cover, and the determination of falling snow should hence be problematic, leads us to wonder what TRMM really records and with what confidence. APHRO_MA_V1101 suffers from insufficient precipitation gauges that are used for the interpolation of APHRODITE data. The data set shows very little precipitation amounts that result in small snow stocks, which are compensated for in the model by high glacier melt during most of the year. HAR10 clearly overestimates precipitation amounts that lead to snowmelt amounts that cannot be compensated for by any means in the model. These findings are based on the comparison of model results and observed discharge. A comparison of each individual data set with in situ data is not feasible (Tustison et al., 2001). Especially in the mountainous regions, such a comparison is strongly biased due to orographic effects, such as precipitation shadows, and precipitation lapse rates (compare ratios for in situ data of sites Bulunkul and Navabad with HAR10 in Fig. 6b). The only viable option to assess precipitation quality thus lies in the evaluation of modelled hydrographs. The reason for that is the characteristic transition from snowmelt into glacier melt into pure base flow that allows for correct snow stocks and correct glacier melt timings and amounts to be discriminated.

Snowmelt is the main contributor to discharge in the early melting phase and also replenishes the groundwater storage. Hence, the amount of snowmelt must result in observed discharge in spring and early summer, but it must also provide the amount of water needed for the observed groundwater discharge during winter. Glacier melt, on the other hand, only contributes to surface runoff and hence does not contribute to groundwater replenishment. It is also temporally restricted to the end of the snow melting phase, when snow cover is depleted (Fig. 3). Because of the temporal decoupling of individual phases, we can infer that a well-represented hydrograph in late spring/early summer can only result from accurately captured snowmelt. If groundwater discharge is then also in agreement with observations, we know that the amount of precipitation that built up the snow storage must be correct. Because glacier melt can compensate for wrong snowmelt amounts in early summer, it is of paramount importance to check all three phases. A compensation by means of overestimated glacier melt is reflected in a consequent mismatch of winter base flow. None of the tested precipitation data sets yielded a satisfying representation of the hydrograph in all three phases without calibration. However, because we have the possibility to determine correct precipitation amounts in this manner, we calibrated intensities of individual data sets. This approach allows for evaluation of the usability of a particular data set for hydrological modelling approaches in the Pamirs.

Based on these three phases we evaluated TRMM, APHRODITE, and HAR data. TRMM provides precipitation amounts that in general lead to a good representation of the snowmelt and winter discharge phase. However, TRMM also shows strong underestimation in individual years. In 2002 and 2004, snow stocks are low and the resulting win- 


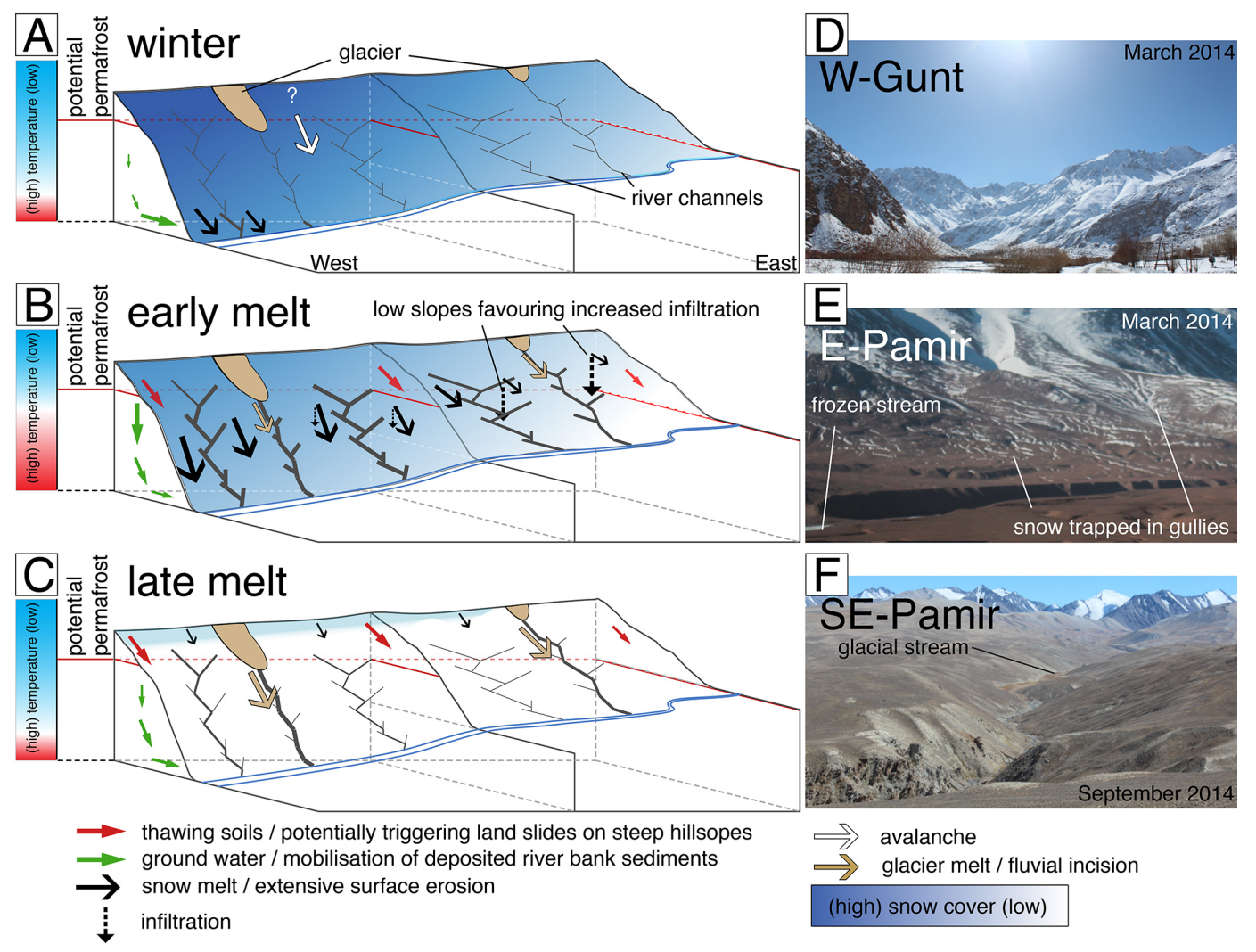

Figure 13. Schematic intra-annual progression of water mobilisation and expected dominant erosional processes. West and east mark endmembers of typical relief (not to scale, and in fact more pronounced). Steep and convex hillslopes in the west contrast with high-elevation, low-relief, and concave hillslope settings in the east. (a) Low temperatures in winter cause interrupted stream flow at high altitudes and limit melt to lowermost altitudes. (b) Rapid and extensive melting affects hillslope water mobilisation and sediment mobilisation downslope. Thawing of frozen soils in especially steep slope regions provides conditions for land sliding. (c) Depleted snow cover limits erosional processes to glaciated catchments. Glacier melt is causing spatially concentrated stream flow, favouring fluvial incision. (d) Precipitation gradients result in extensive snow cover in the western Pamirs, and little snow cover in the eastern Pamirs (e) in winter. (f) Glacier-melt-induced incision at the watershed divide south of Bulunkul.

ter discharge strongly underestimates observed discharge. APHRODITE shows this underestimation every year, which identifies a general underestimation of precipitation amounts in the snow accumulation phase. HAR overestimates precipitation, leading to too strong snowmelt. Instead of rejecting the model approach itself - because there is no accurate data set - we further explore the data sets' usability. Correcting a data set that shows only weak correlation with in situ data lacks a systematic approach. Thus, we focused on the HAR10 data set that showed significant and temporally independent correlation with in situ measurements (Fig. 5). By calibrating HAR10's precipitation intensities we achieve the best representation of the hydrograph in all three phases. This allowed us to derive a correction factor for HAR 10 of 0.37 , which is lower than the factor of 0.56 which Mölg et al. (2013) derived from comparison of HAR and precipitation gauges in Tibet. The difficulty in obtaining meaningful correction factors from comparison with in situ data is demonstrated in Fig. 6b. If we only had data available for site Nav- abad (corresponding factor of 0.38 ), we would be able to directly obtain a good estimate. However, sites that probably experience strong orographically induced biases like site Bulunkul (corresponding factor of 0.11) lead to significantly different estimates, which is why our initial downscaling did not result in a good representation of the hydrograph.

Even though APHRODITE and TRMM show weaker and less systematic correlation with in situ data, their application in the model yielded NSE $>0.8$. This shows that the NSE does not allow for the quality of precipitation data to be assessed. In fact, a randomly resampled HAR10 $(258 \mathrm{~mm})$ data set, for example, still yields a NSE of 0.76 . This clearly underlines that the amount of precipitation rather than the temporal distribution will allow a model to perform well in terms of NSE. In summary, the use of regional/global data sets for studies on glacier retreat and precipitation amounts in the greater Pamir, and western Tibetan region (Lutz et al., 2014) consequently raises issues about the representativeness of obtained results where there is no possibility to validate 
obtained results in the presented way. Even though total precipitation amounts seem most important for a model to perform well, the temporal distribution is important because it determines whether water is stored as snow during the accumulation period. In contrast to TRMM and APHRODITE, HAR 10 provides $20 \%$ more of its annual precipitation in the winter half-year (Fig. 10). This results in up to $86 \%$ of precipitation provided as snow (modelled). Better-performing models show higher fractions of precipitation as snowfall, which matches the assumption that most moisture is supplied by the Westerlies in winter and early spring (Immerzeel et al., 2009; Pu et al., 2007; Xiao et al., 2002).

\subsection{Hydrological cycle}

The analysis of the individual water cycle components all suggest a substantial amount of deep groundwater discharge $\left(Q_{\text {bas2 }}\right)$, a not yet fully constrained fast retention storage discharge $\left(Q_{\text {bas } 1}\right)$, and glacier runoff ( $\left.Q_{\text {glac }}\right)$ (Figs. 10, 9). This observation is best explained by comparing the temporal relationships of discharge with (1) precipitation, (2) with effective precipitation $\left(P_{\text {eff }}\right)$ (which we define here as all liquid stream water contribution from rainfall, snowmelt, and glacier melt), and (3) with temperature (Fig. 12a-f). The concept of the hysteresis plots is that an immediate response of river discharge to water contribution into the system will result in plotted values along a $1: 1$ line. In contrast, if the different storage compartments induce a lag of response, the points are deflected from this $1: 1$ line and describe a hysteresis effect. Points aligned below the $1: 1$ line (less discharge than contribution) describe a storage recharge, and above the $1: 1$ line they describe a depletion of storage.

The overall best-performing models with either TRMM3B42 V7 or HAR10 precipitation data show a strong decoupling of precipitation and discharge (Fig. 12a, d) that results in an almost $90^{\circ}$ rotated picture compared to the $1: 1$ relationship. This results in a water surplus from October to May and higher discharge than water input from June to September. This decoupling is very prominent and can also be inferred from Fig. 9. TRMM (308 mm) and HAR10 $(258 \mathrm{~mm})$ show a similar behaviour (Fig. 12d), with the biggest difference being a shift towards more precipitation for TRMM $(308 \mathrm{~mm})$. APHRO $(200 \mathrm{~mm})$ shows a systematically different behaviour that cannot be explained by a simple shift in precipitation amounts.

In comparison to precipitation, the relation between discharge and $P_{\text {eff }}$ is more immediate (Fig. 12b, e) and shows a similar shape to a rainfall-dominated system in the Himalayas (Fig. 12c). The anticlockwise hysteresis for the rainfall-dominated catchment (Fig. 12c) depicts water retardation in aquifers as has been reported by Andermann et al. (2012b). The biggest difference between the Pamirs and the Himalayas is the long, flat tail of the hysteresis loop in winter (Fig. 12e), when stream flow almost entirely originates from groundwater discharge, while no effective precipitation oc- curs. The differences between the individual hysteresis loops with $P_{\text {eff }}$ (Fig. 8e) for different precipitation data sets are smaller than for the hysteresis loops with actual precipitation (Fig. 12d). This fact also confirms the need to use a data set that provides a sufficient amount of winter precipitation. Using APHRO $(154 \mathrm{~mm})$ and HAR10 $(172 \mathrm{~mm})$ precipitation data results in systematically different shapes (shaded area at lowest specific discharge in Fig. 12e), which indicates a minimum threshold value for precipitation needed to obtain the systematic hysteresis loop with the long, flat tail in winter. These low-precipitation data sets also show significantly lower values of Tbase $\mathrm{g}$ to make glacier melt start more early to account for too little snow stocks.

This underlines, above all, the elusiveness of quality assessment for precipitation data sets within glacier melt/snowmelt-runoff studies if no cross-validations with, for example, snow cover data are conducted. It also leads to the conclusion that an accurate estimation of temperatures can vastly improve certainty in such studies. HAR 10 and MODIS temperatures used in this study seem to provide good estimates, but a validation with in situ data at very high altitude should certainly be in focus for future studies. The overall better performance of MODIS temperatures suggests that the finer resolution significantly improves the representation of the hydrological cycle, probably because snow and glacier melt is captured better. However, HAR10, with its coarser resolution, still proves to be a viable option. This might be of special interest for studies conducted at a larger scale. The strong dependence of discharge on temperature is shown in Fig. 12f. The dependency is not straightforward but shows a small clockwise loop in the summer half-year $\left(T>0{ }^{\circ} \mathrm{C}\right)$ and a small anticlockwise loop in the winter half-year $\left(T<0^{\circ} \mathrm{C}\right)$ along with different slopes for the individual half-years. Due to a decreasing snow stock in summer (Fig. 9a), the meltwater response to an equal temperature decreases. Given an equal temperature in winter, the initial higher groundwater storage will cause more discharge at the beginning of the season than towards the end (Fig. 9b). The strong impact of temperature on the runoff regime in the Pamirs has already been reported by Schiemann et al. (2007), who found a response of tropospheric temperatures (affecting melting in the Pamirs) to changes in ISM intensity.

Because our model prevents glacier runoff from infiltrating into the soil and subsequent storages, the winter groundwater discharge mainly originates from snowmelt of the preceding melting period. This is reasonable because glacier melts occur locally and at high altitudes. Melt products are rapidly channelised. Changes in precipitation patterns and/or intensities towards less winter precipitation or shortened snow accumulation periods in the Pamirs (Kure et al., 2013) would therefore severely affect winter discharge in the consecutive year. Additionally, an increase in summer precipitation would not necessarily be noticed hydrograph-wise due to higher interception and evapotranspiration, which is essentially limited to the summer months (Fig. 9a). This is 
also the reason why TRMM (308 $\mathrm{mm})$ with a higher portion of summer precipitation in comparison to HAR10 (258 mm) produces more glacier runoff, and a more negative glacier mass balance despite providing overall more precipitation. The water balance is here compensated for by increased summer actET (43\% of annual precipitation or $132 \mathrm{~mm}$ for TRMM $(308 \mathrm{~mm}) ; 28 \%$ of annual precipitation or $72 \mathrm{~mm}$ for HAR10 $(258 \mathrm{~mm}))$. Therefore, temperature in particular affects not only timing and magnitude of melting but due to its effect on potential evapotranspiration and phenology - also the amount of annual net discharge with regards to actET. The compensation of higher summer precipitation by higher actET also implies that summer precipitation only marginally contributes to surface runoff in general.

If global temperatures increase, a shift towards more liquid precipitation would also imply changing hazard potentials for floods (smaller snow stocks and reduced water amounts for melting) and avalanches (liquid precipitation provided on existing snow cover; Hägeli and McClung, 2003; Zischg et al., 2005). Weather variability, too, has a significant impact on the hydrological regime, as can be inferred from the strong interannual hydrograph variability (Fig. 8 and Sect. 2). Pohl et al. (2015) show complex effects of weather variability on water availability and storage in the greater Pamir region. The complexity results from the interplay of temperature, precipitation amounts and timings, and resulting snow cover. This affects the fate of glaciers on annual rather than climatological timescales and leads to the occurrence of floods and droughts.

We justify our approach of using a wide range of correction factors for the precipitation data sets used, because neither snow stocks nor glacier melt can be validated with in situ data. By reproducing the early melting period as accurately as possible, we can better constrain glacier melt. The compensation by means of $Q_{\text {glac }}$ is independent of the parameterisation of the degree-day factor for glacier ice $\mathrm{TMF}_{\mathrm{gi}}$. The modelled $30 \% Q_{\text {glac }}$ of annual $Q_{\text {tot }}$ with HAR10 $(258 \mathrm{~mm})$ and $40 \%$ with TRMM $(308 \mathrm{~mm})$ show that $Q_{\text {glac }}$ is sensitive to the modelled water balance until the transition from snow into glacier melt occurs. This highlights the difficulty of modelling glacier melt accurately without actual in situ measurements. Because glacier melt occurs at the end of the melting period, when snow stocks are diminished (Fig. 9a), wrongly assessed snow stocks at the beginning of the melting period and the resulting water balance at the transition point will force the model to compensate by adjusting $Q_{\text {glac }}$. Because HAR10 $(258 \mathrm{~mm})$ delivers the best representation of the hydrograph in the early melting period, we assume $Q_{\text {glac }}$ derived from this model setup to provide the most reliable results.

Our results support findings of several studies that have pointed out a shift from rainfall towards more snow- and glacier-melt-dominated systems towards the west of the Himalayan syntaxis (Bookhagen and Burbank, 2010; Immerzeel et al., 2009; Lutz et al., 2014). We also find sim- ilarities to findings by Andermann et al. (2012b), who report a large impact of groundwater discharge on the annual hydrological cycle in the central Himalayas. Our modelled groundwater storage capacities $(\approx 100 \mathrm{~mm})$ are comparable to a high-alpine, glaciated but rainfall-dominated catchment in their study. Groundwater turnover times of 200-400 days (GWK2) in this study correspond to typical values found for fissured rock aquifers (Schwarze et al., 1999), which also characterise the central Himalayan catchments (Andermann et al., 2012b).

We find a substantial concordance with several glaciological studies in the Pamirs and surrounding regions. Of course, the obtained values of $\approx 1 \mathrm{~mm}^{\circ} \mathrm{C}^{-1} \mathrm{day}^{-1}$ for $\mathrm{TMF}_{\mathrm{gi}}$ that build the basis for the obtained modelling results differ from common literature values of $7-10 \mathrm{~mm}^{\circ} \mathrm{C}^{-1} \mathrm{day}^{-1}$ (Hock, 2003). We argue that our value is actually an average representing the entire glacier area and not a single point. This is due to the coarse resolution $\left(0.05^{\circ}\right.$ for MOD $11 \mathrm{C} 1 \mathrm{~V} 5$ and $\approx 0.09^{\circ}$ for HAR 10 ) of the temperature data sets that provide the same temperature for the entire glacier area. Based on this simplification, this apparently low value would consequently correspond to a much higher value if the actual temperature gradient along the glaciers were considered. What the resulting value would be is highly speculative considering the spatial variability in glacier melting dynamics and its analysis (Barrand et al., 2010). To a lesser degree, the simple glacier module used here does not account for the transformation of snow into ice, and hence more snow is available for snowmelt. In contrast to $\mathrm{TMF}_{\mathrm{gi}}$, glacier mass balances can be compared more easily because the glacier as a whole is considered. Haritashya et al. (2009) report average retreat rates of $10.9 \mathrm{~m} \mathrm{yr}^{-1}$ (1976-2003) based on model predictions and imagery analysis for the Wakhan Range, just south of the study area (Fig. 2), and Khromova et al. (2006) report a decrease in glacier area of $11.6 \%$ (1990-2001) for the northern Pamirs and a general negative mass balance trend for the Pamirs between 1970 and 2000. Lutz et al. (2013) used a regionalised glacier mass balance model to evaluate climate change scenarios in the Amu Darya catchment (comprising most of the Pamirs). They predicted $\approx-0.6$ to $-0.7 \mathrm{mw}$.e. $\mathrm{yr}^{-1}$ for the period 2007 to 2017 . Contradicting findings of Gardelle et al. (2013), stating positive glacier mass balances for the Pamir region between 1999 and 2011, might simply be related to the very local study location further northwest around the Abramov and Fedchenko glaciers. This region is assumed to receive anomalously high precipitation compared to the region encompassing the Gunt and Shakhdara catchments (Ménégoz et al., 2013; Fuchs et al., 2013) and hence provides a very different climatic setting. Sorg et al. (2012), on the other hand, presented negative glacier mass balances for the Abramov Glacier of $\approx-1 \mathrm{mw}$.e. $\mathrm{yr}^{-1}$ for the period from 1970 to 1999.

Few limited monthly relative humidity data of 2004 for three sites show a good agreement for the winter months 


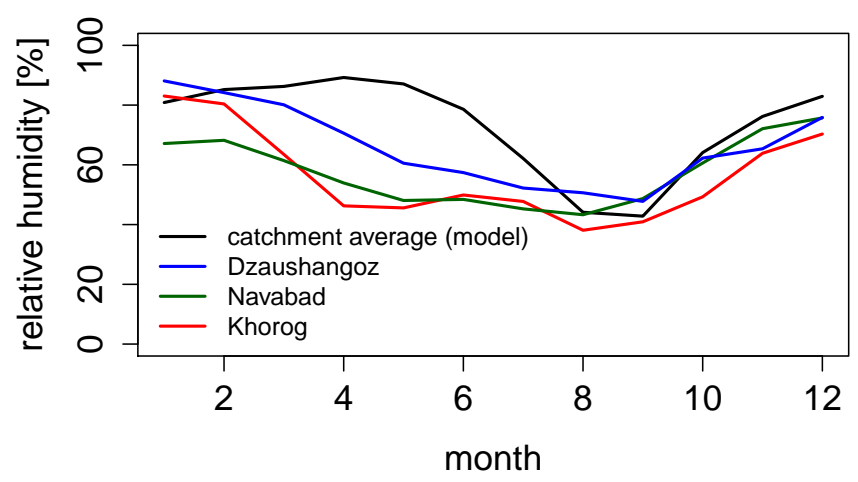

Figure 14. Modelled monthly average relative humidity in the Gunt catchment vs. in situ data of three individual sites for 2004. Average altitude of modelled data is $4300 \mathrm{~m}$ a.s.1., contrasting with considerably lower altitudes of the three sites (see Fig. 1) indicating already diminished snow cover and soil moisture (compare to average snowmelt timing in Fig. 9).

and the end of the melting period (Fig. 14) with modelled basin average values. During the early melting period, modelled values are much higher, which is most likely due to the location of the three in situ sites at low altitude. They are hence not representative of the basin average at $4300 \mathrm{~m}$ a.s.l., which, in comparison to these sites, still has a significant snow cover (see Fig. 3). Hence, the three sites likely have already depleted snow stocks and dried-out soils that contrast with basin average conditions where main snowmelt occurs in June (see Fig. 9a). We cannot validate actET due to the absence of in situ measurements. However, our modelled values for actET are corroborated by the work of Bookhagen and Burbank (2010), stating actET values less than $100 \mathrm{~mm} \mathrm{yr}^{-1}$ for the Pamir region based on satellite derived data from MODIS. The precompiled MODIS MOD16 (Mu et al., 2011) product for evapotranspiration is not feasible in the study area because only values for vegetated areas are given (according to MODIS MCD12Q1 land cover classification $\approx 24 \%$ of the study area).

\subsection{Modelling concept}

We find the J2000g model to be a good choice for our approach due to its simplicity and low number of calibration parameters compared to more physically based models. The choice of a rather simple model is, furthermore, justified by the high level of uncertainties within the precipitation data sets used and difficult-to-restrict soil and aquifer properties. From a technical point of view, the integration of various data sets in different spatial resolutions synergises with the chosen raster-based HRU approach. Due to the model's lack of dependency on the input raster's spatial resolution, data sets can easily be exchanged. One limitation of J2000g is its soil module in its current form, which is not designed for the presented environment and is unable to capture re- tardation effects from refreezing of meltwater in snowpacks, frozen soils, and routing through various sediment deposits. This is reflected in the very low calibrated values for FCA and LVD that withdraw the soil's water storage capacity and cause most of the water to be transferred to the underlying linear storages, thus avoiding treatment within the soil module. This results in almost no $Q_{\text {surf }}$ (Fig. 10) and instead representation of these processes by $Q_{\text {bas } 1}$.

\subsection{Implications for surface processes}

Based on the derived spatiotemporal distribution of individual water components, we suggest a conceptual model for expected surface processes (Fig. 13). The rapid melting of snow cover in the short period between May and July during which the bulk of the annual precipitated water is released (Figs. 9 and $13 \mathrm{~b}$ ) causes spatiotemporally limited water availability. The knowledge about the extensive release of snowmelt is a prerequisite for an adequate erosion modelling (Ollesch et al., 2005, 2006). Rising temperatures during spring to summer lead to an increase in altitude where snowmelt occurs and thus affect the geomorphological boundary conditions, such as hillslope angles, which seem to affect the mobilisation of sediments (Iida et al., 2012; Ali and De Boer, 2010). The increase in soil moisture content that coincides with the snowmelt progression is known to contribute to hillslope mass wasting and landslides (Iverson, 2000; Dietrich et al., 1992). Intense precipitations generate strong direct runoff and sediment supply from hillslopes in the Himalayas (Andermann et al., 2012a). The rapid release of snowmelt provides similar conditions in terms of intensity. However, due to the spatial (altitude) limitation and a rapid water channelisation, new concepts to relate specific topographic characteristics, sediment provenance, and runoff to erosion are required.

During late summer, snow stocks are depleted and glacier runoff is the essential surface runoff component (Fig. 13c and f). This implies that erosional processes, including sediment transport and fluvial incision, are basically limited to glaciated catchments during that period. The efficacy of proglacial sediment evacuation is in agreement with the spatial distribution of glaciers and the topography in the Gunt catchment, as well as in the rest of the Pamirs. This can be inferred from the decreasing trend in glaciated area (Fig. 2) in west-east direction, which coincides with deep incision and steep catchments in the western parts and low-relief, gently sloping areas in the east (Fuchs et al., 2014a, b). Low precipitation and snow cover in the east suggest generally low sediment mobilisation. But trapping of snow in gullies (see Fig. 13d and e) might favour channelisation of snowmelt, similar to the glacier melt in late summer, reducing extensive erosion even more. The western Pamir margins provide an orographic barrier for moisture flux into the Pamirs' interior. Associated strong glaciation at the margins (Fuchs et al., 2013) and high relief provide the boundary conditions for 
glacier headwall retreat and debris evacuation of glaciated catchments (Scherler et al., 2011). Low mean annual temperatures and high interannual variations (Fig. 1) provide conditions for efficient frost cracking (e.g. Andersen et al., 2015; Egholm et al., 2015). The strong negative precipitation gradient towards the east partly impedes the effective removal of accumulated alluvium by means of stream flow. In contrast, the zone of potential permafrost in the western part coincides with steep slopes at the mountain ridges (Fig. 13c). Hence, frost cracking might trigger rock slides into the intermittent tributary river beds, thus providing supply for the subsequent snow melting period.

In winter, freezing temperatures and the lack of liquid precipitation limit sediment flux to the low-altitude river channels, which are fed almost entirely by groundwater discharge (Figs. 9b and 13a). Areas with high precipitation and steep slopes in the western part of the catchment are prone to periglacial debris flows, rock slides, and ice avalanches (Gruber and Mergili, 2013), which deposit debris and sediments close to the river channel. These can eventually be remobilised in summer by high discharge from snow and glacier melt.

The presented concept can be applied to the greater Pamir region. It is known that, in most mountain ranges, longterm annual rainfall amplitudes and the temporal distribution of precipitations affect erosion rates (e.g. Gabet et al., 2004), whereas high-intensity events dominantly control incision rates (e.g. Snyder et al., 2003; Lague et al., 2005). The arid conditions in the eastern Pamirs result in a 10-fold faster valley deepening (compared to basin-wide erosion) at the southern and south-western Pamir margin (Fuchs et al., 2014b). Only the north-western margin differs from this pattern. There, higher Westerlies-derived winter precipitation and increased summer precipitation in the area of the Fedchenko Glacier allow for a certain adjustment of erosion to the roughly 3-fold faster incision along the Panj River (Fuchs et al., 2014a). The latter resembles processes described in the western Himalayas. There, the availability of water increases the sediment flux from hillslopes out of basins, driving high basin-wide erosion and less pronounced valley deepening. The seasonality of runoff generation from melt in the Pamirs and from rainfall in the Himalayas shows similar characteristics of stream flow in the main river channel (Fig. 12b and c). However, extensive runoff on hillslopes in the Himalayas contrast channelised runoff in large parts of the Pamirs. The required climatic conditions for extensive erosion are thus not often met. While individual high-magnitude storm events are very effective for erosion in the Himalayas (Bookhagen and Burbank, 2010), it would require an equivalent of positive winter precipitation (snow stocks) and positive summer temperature anomalies to produce similar phenomena in the Pamirs.

\section{Conclusions}

A combination of RCM and remote sensing data allows an accurate retrieval of the hydrological cycle using the $\mathrm{J} 2000 \mathrm{~g}$ model. With $\approx 80 \%$ of precipitation being supplied as snow, the water input is dominated by snowmelt. The interaction of temperature and the spatiotemporal distribution of precipitation are the factors characterising the region's hydrology. The presented precipitation-discharge hysteresis emphasises this finding. Due to the strong temperature-discharge relationship, the most influential precursors leading to interannual discharge variability are winter precipitation (resulting in large snow stocks) and abrupt increases in temperature (triggering the melt). More liquid precipitation, as is expected in a changing climate, does not result in significantly increasing discharge but in more evapotranspiration.

About $200 \mathrm{~mm}$ (four-fifths) of the annual discharge takes place in summer as a result of snow and glacier melt, and $\approx 50 \mathrm{~mm}$ (one-fifth) in winter. Because winter discharge is mainly sustained by groundwater discharge, and because groundwater originates from snowmelt in summer, streamflow at any time of the year originates from melting of snow and ice. The contribution from glacier melt to annual discharge is about $30 \%$.

A distinct transition from snow into glacier melt occurs during July and August, when snow stocks are depleted and temperature peaks. Intense snowmelt is concentrated in the short period between May and July, and glacier melt between June and September. During the rest of the year, groundwater discharge provides a continuous flow in the main channels. The different sources of liquid water imply different erosional processes. Extensive snowmelt at high altitudes affects entire hillslopes. Glacier melts are rapidly channelised and therefore allow for a very spatially limited contribution to surface processes in the affected catchments. At lower altitudes groundwater discharge provides spatially even more limited water flow in the main channels.

The seasonality in river discharge of the Gunt River is similar to what can be observed in the central Himalayas. However, water mobilisation from snow and glacier melt provides fundamentally different conditions for surface processes compared to mobilisation from rainfall. Therefore, an accurate assessment of surface processes in the Pamirs is bound to accurate estimates of spatiotemporal dynamics in hydrology. In return, this might provide insights into a variety of interdisciplinary studies, e.g. on landscape evolution, by providing high spatiotemporal resolution data to deepen our understanding of climate/weather variability impacts on erosional processes (e.g. DiBiase and Whipple, 2011; Champagnac et al., 2012; Dietrich et al., 1992; Iverson, 2000; Montgomery and Brandon, 2002). The here presented conceptual model of interactions between water mobilisation and expected Earth surface processes also sheds some light on the very unusual discrepancy between erosion and incision rates in the Pamirs (Fuchs et al., 2013, 2014b). 
Mean hydrological results show a negative glacier mass balances of $\approx-0.6 \mathrm{mw}$.e. $\mathrm{yr}^{-1}$, which points to a potential diminution of glaciers. This would consequently have a strong impact on hydropower and agriculture downstream. In combination with a sooner onset of the melting season, water availability would change in amount and temporal distribution, which will demand adapted agricultural strategies. It is unclear whether and how much climate change will affect the distribution of Westerlies- or ISM-induced precipitation and their effect on the hydrological cycle in the Pamirs. This is to a large extent the result of lacking data - both accurate spatially distributed data sets and validation data.

The study area is dominated by Westerlies with a noticeable but minor summer precipitation influence. The lag appearing during summer for the precipitation-discharge hysteresis reveals the influence of a different circulation system other than only Westerlies. Our analysis of different widely used precipitation data sets provides a valuable basis for further studies in western Tibet and similar environments. Key findings are (1) that APHRO_MA_V1101 underestimates actual precipitation by a factor of $\approx 2$ and should not be applied in the central Pamirs, (2) that HAR10 overestimates (by a factor of 2 to 3) but shows a good representation of spatiotemporal distribution, and (3) that TRMM3B42 V7 most likely suffers from inaccurate precipitation retrieval over existing snow cover and is therefore not a good choice for the present environment. In summary, we find HAR10 to be the best choice for precipitation, but with the crucial need to downscale intensities. For temperature, both MODIS land surface temperature data (as a proxy for air temperature) and, to a lesser extent, because of the coarser resolution, HAR10 temperature data provide reliable estimates of air temperature. These can be used for snow and glacier melt studies and might provide superior estimates compared to simple spatial interpolation of in situ data based on lapse rates. 
Appendix A

Relative humidity was calculated based on GLDAS_NOAH025SUBP_3H vapour pressures and temperatures according to the formulas provided via email by the LP DAAC:

$$
\begin{aligned}
\mathrm{MR} & =\frac{\mathrm{SH}}{1-\mathrm{SH}}, \\
E_{\mathrm{a}} & =\frac{p \times \mathrm{MR}}{\mathrm{MR}+0.622}, \\
E_{\mathrm{s}} & =611.2 \exp \frac{17.67 \times T}{T+243.5}, \\
\mathrm{RH} & =E_{\mathrm{a}} / E_{\mathrm{s}} \times 100,
\end{aligned}
$$

where $\mathrm{SH}$ is the specific humidity in $\mathrm{kg} \mathrm{kg}^{-1}$, MR is the mixing ratio, $E_{\mathrm{a}}$ is the actual vapour pressure in $\mathrm{Pa}, p$ is the atmospheric pressure in $\mathrm{Pa}, E_{\mathrm{S}}$ is the saturated vapour pressure in Pa, $T$ is the temperature in ${ }^{\circ} \mathrm{C}$, and $\mathrm{RH}$ is the relative humidity in $\%$. The equations were directly implemented into the script, extracting the data. 
Acknowledgements. This work is part of the BMBF (Federal Ministry of Education and Research) research programme PAMIR (FKZ 03G0815) within the CAME (Central Asia and Tibet: Monsoon dynamics and geo-ecosystems) project and funded by the BMBF. MODIS MOD11C1 and MCD12Q1 data are distributed by the Land Processes Distributed Active Archive Center (LP DAAC), located at the US Geological Survey (USGS) Earth Resources Observation and Science (EROS) Center (https://lpdaac.usgs.gov). APHRODITE results from a collaboration of the Research Institute for Humanity and Nature and the Meteorological Research Institute of the Japan Meteorological Agency. We thank the State Administration for Hydrometeorology of Tajikistan for their cooperation. We would like to thank Samuel Dixon and two anonymous reviewers for their comments, and we thank Michele Koppes for suggestions and ideas that helped to improve the manuscript. The PAMIR team further includes Christiane Meier, Stephan Weise, Karsten Osenbrück, Stefan Geyer, Tino Rödiger, Christian Siebert, and Wolfgang Busch.

Edited by: M. Koppes

\section{References}

Ad-hoc-Arbeitsgruppe Boden: Bodenkundliche Kartieranleitung, 5th Edn., Bundesanstalt für Geowissenschaften und Rohstoffe in Zusammenarbeit mit den Staatlichen Geologischen Diensten, Hannover, Germany, 2005.

Agakhanyantz, O. E. and Lopatin, I. K.: Main characteristics of the ecosystems of the Pamirs, USSR, Arctic Alpine Res., 10, 397407, doi:10.2307/1550770, 1978.

Aizen, V. B., Mayewski, P. A., Aizen, E. M., Joswiak, D. R., Surazakov, A. B., Kaspari, S., Grigholm, B., Krachler, M., Handley, M., and Finaev, A.: Stable-isotope and trace element time series from Fedchenko glacier (Pamirs) snow/firn cores, J. Glaciol., 55, 275291, doi:10.3189/002214309788608787, 2009.

Ali, K. F. and De Boer, D. H.: Spatially distributed erosion and sediment yield modeling in the upper Indus River basin, Water Resour. Res., 46, W08504, doi:10.1029/2009WR008762, 2010.

Allen, R. G., Pereira, L. S., Raes, D., and Smith, M.: Crop Evapotranspiration - Guidelines for Computing Crop Water Requirements, 56th edn., FAO - Food and Agriculture Organization of the United Nations, Rome, Italy, 1998.

Andermann, C., Bonnet, S., and Gloaguen, R.: Evaluation of precipitation data sets along the Himalayan front, Geochem. Geophy. Geosy., 12, Q07023, doi:10.1029/2011GC003513, 2011.

Andermann, C., Bonnet, S., Crave, A., Davy, P., Longuevergne, L., and Gloaguen, R.: Sediment transfer and the hydrological cycle of Himalayan rivers in Nepal, CR Geosci., 344, 627-635, doi:10.1016/j.crte.2012.10.009, 2012a.

Andermann, C., Longuevergne, L., Bonnet, S., Crave, A., Davy, P., and Gloaguen, R.: Impact of transient groundwater storage on the discharge of Himalayan rivers, Nat. Geosci., 5, 127-132, doi:10.1038/ngeo1356, 2012b.

Andermann, C., Crave, A., Gloaguen, R., Davy, P., Bonnet, S.: Connecting source and transport: Suspended sediments in the Nepal Himalayas, Earth Planet Sc. Lett., 351-352, 158-170, doi:10.1016/j.epsl.2012.06.059, 2012c.

Andersen, J. L., Egholm, D. L., Knudsen, M. F., Jansen, J. D., and Nielsen, S. B.: The periglacial engine of mountain erosion - Part
1: Rates of frost cracking and frost creep, Earth Surf. Dynam. Discuss., 3, 285-326, doi:10.5194/esurfd-3-285-2015, 2015.

Arendt, A., Bliss, A., Bolch, T., Cogley, J., Gardner, A., Hagen, J.-O., Hock, R., Huss, M., Kaser, G., Kienholz, C., Pfeffer, W., Moholdt, G., Paul, F., Radić, V., Andreassen, L., Bajracharya, S., Barrand, N., Beedle, M., Berthier, E., Bhambri, R., Brown, I., Burgess, E., Burgess, D., Cawkwell, F., Chinn, T., Copland, L., Davies, B., Angelis, H. D., Dolgova, E., Filbert, K., Forester, R., Fountain, A., Frey, H., Giffen, B., Glasser, N., Gurney, S., Hagg, W., Hall, D., Haritashya, U., Hartmann, G., Helm, C., Herreid, S., Howat, I., Kapustin, G., Khromova, T., König, M., Kohler, J., Kriegel, D., Kutuzov, S., Lavrentiev, I., LeBris, R., Lund, J., Manley, W., Mayer, C., Miles, E., Li, X., Menounos, B., Mercer, A., Mölg, N., Mool, P., Nosenko, G., Negrete, A., Nuth, C., Pettersson, R., Racoviteanu, A., Ranzi, R., Rastner, P., Rau, F., Raup, B., Rich, J., Rott, H., Schneider, C., Seliverstov, Y., Sharp, M., Sigurðsson, O., Stokes, C., Wheate, R., Winsvold, S., Wolken, G., Wyatt, F., and Zheltyhina, N.: Randolph Glacier Inventory - A Dataset of Global Glacier Outlines: Version 4.0., http://www.glims.org/RGI/, 2014.

Awange, J., Fleming, K., Kuhn, M., Featherstone, W., Heck, B., and Anjasmara, I.: On the suitability of the $4^{\circ} \times 4^{\circ}$ GRACE mascon solutions for remote sensing Australian hydrology, Remote Sens. Environ., 115, 864-875, doi:10.1016/j.rse.2010.11.014, 2011.

Barrand, N. E., James, T. D., and Murray, T.: Spatio-temporal variability in elevation changes of two high-Arctic valley glaciers, J. Glaciol., 56, 771-780, doi:10.3189/002214310794457362, 2010.

Batu, V.: Aquifer Hydraulics: a Comprehensive Guide to Hydrogeologic Data Analysis, John Wiley \& Sons, Inc., Hoboken, NJ, USA, 1998.

Bookhagen, B. and Burbank, D. W.: Toward a complete Himalayan hydrological budget: spatiotemporal distribution of snowmelt and rainfall and their impact on river discharge, J. Geophys. Res., 115, 1-25, doi:10.1029/2009JF001426, 2010.

Breckle, S. W. and Wucherer, W.: Vegetation of the Pamir (Tajikistan), in: Land Use Change and Mountain Biodiversity, edited by: Spehn, E. M., Körner, C., and Liberman, M., CRC Press, Boca Raton, FL, USA, chap. 16, 225-237, doi:10.1201/9781420002874.ch16, 2006.

Breuer, L. and Frede, H.: PlaPaDa - an online plant parameter data drill for eco-hydrological modelling approaches, available at: http://www.uni-giessen.de/ gh1461/plapada/plapada.html (last access: 10 December 2014), 2003.

Burbank, D. W., Blythe, A. E., Putkonen, J., Pratt-Sitaula, B., Gabet, E., Oskin, M., Barros, A., and Ojha, T. P.: Decoupling of erosion and precipitation in the Himalayas, Nature, 426, 652-655, doi:10.1038/nature02187, 2003.

Champagnac, J.-D., Molnar, P., Sue, C., and Herman, F.: Tectonics, climate, and mountain topography, J. Geophys. Res., 117, B02403, doi:10.1029/2011JB008348, 2012.

Chen, F. and Dudhia, J.: Coupling an Advanced Land SurfaceHydrology Model with the Penn State-NCAR MM5 Modeling System. Part I: Model implementation and sensitivity, Mon. Weather Rev., 129, 569-585, doi:10.1175/15200493(2001)129<0569:CAALSH>2.0.CO;2, 2001.

Chen, F., Manning, K. W., LeMone, M. A., Trier, S. B., Alfieri, J. G., Roberts, R., Tewari, M., Niyogi, D., Horst, T. W., Oncley, S. P., Basara, J. B., and Blanken, P. D.: Description and evaluation 
of the characteristics of the NCAR High-Resolution Land Data Assimilation System, J. Appl. Meteorol. Clim., 46, 694-713, doi:10.1175/JAM2463.1, 2007.

Chernova, L. P.: Influence of mass balance and run-off on reliefforming activity of mountain glaciers, Ann. Glaciol., 2, 69-70, 1981.

Cooper, H. J., Lanier, R. J., Fuelberg, H. E., and Watson, A. I.: Comparing the operational capabilities of the site specific hydrologic predictor (SSHP) and a fully distributed hydrological model (MIKE SHE) using WSR-88 radar rainfall inputs over a small basin in Florida, in: 20th Conference on Hydrology, Atlanta, GA, 28 January-2 February 2006, Am. Meteorol. Soc, available at: http://ams.confex.com/ams/Annual2006/techprogram/ session_19002.htm (last access: 10 December 2014), 2006.

Dadson, S. J., Hovius, N., Chen, H., Dade, W. B., Hsieh, M.-L., Willett, S. D., Hu, J.-C., Horng, M.-J., Chen, M.-C., Stark, C. P., Lague, D., and Lin, J.-C.: Links between erosion, runoff variability and seismicity in the Taiwan orogen, Nature, 426, 648-51, doi:10.1038/nature02150,2003.

Daniel, E. B.: Watershed modeling and its applications: a state-of-the-art review, Open Hydrol. J., 5, 26-50, doi:10.2174/1874378101105010026, 2011.

Dee, D. P., Uppala, S. M., Simmons, A. J., Berrisford, P., Poli, P., Kobayashi, S., Andrae, U., Balmaseda, M. A., Balsamo, G., Bauer, P., Bechtold, P., Beljaars, A. C. M., van de Berg, L., Bidlot, J., Bormann, N., Delsol, C., Dragani, R., Fuentes, M., Geer, A. J., Haimberger, L., Healy, S. B., Hersbach, H., Hólm, E. V., Isaksen, L., Kållberg, P., Köhler, M., Matricardi, M., McNally, A. P., Monge-Sanz, B. M., Morcrette, J.-J., Park, B.K., Peubey, C., de Rosnay, P., Tavolato, C., Thépaut, J.-N., and Vitart, F.: The ERA-Interim reanalysis: configuration and performance of the data assimilation system, Q. J. Roy. Meteor. Soc., 137, 553-597, doi:10.1002/qj.828, 2011.

Deus, D., Gloaguen, R., and Krause, P.: Water balance modeling in a semi-arid environment with limited in situ data using remote sensing in Lake Manyara, East African Rift, Tanzania, Remote Sens., 5, 1651-1680, doi:10.3390/rs5041651, 2013.

DiBiase, R. A. and Whipple, K. X.: The influence of erosion thresholds and runoff variability on the relationships among topography, climate, and erosion rate, J. Geophys. Res., 116, F04036, doi:10.1029/2011JF002095, 2011.

Dietrich, W. E., Wilson, C. J., Montgomery, D. R., McKean, J., and Bauer, R.: Erosion thresholds and land surface morphology, Geology, 20, 675-679, 1992.

Dietz, A., Conrad, C., Kuenzer, C., Gesell, G., and Dech, S.: Identifying Changing Snow Cover Characteristics in Central Asia between 1986 and 2014 from Remote Sensing Data, Remote Sens., 6, 12752-12775, doi:10.3390/rs61212752, 2014.

Duan, Q., Sorooshian, S., and Gupta, V.: Optimal use of the SCEUA global optimization method for calibrating watershed models, J. Hydrol., 158, 265-284, doi:10.1016/0022-1694(94)900574, 1994.

Egholm, D. L., Andersen, J. L., Knudsen, M. F., Jansen, J. D., and Nielsen, S. B.: The periglacial engine of mountain erosion - Part 2: Modelling large-scale landscape evolution, Earth Surf. Dynam. Discuss., 3, 327-369, doi:10.5194/esurfd-3-327-2015, 2015.

Ek, M. B., Mitchell, K. E., Lin, Y., Rogers, E., Grunmann, P., Koren, V., Gayno, G., and Tarpley, J. D.: Implementation of Noah land surface model advances in the National Centers for Environmental Prediction operational mesoscale Eta model, J. Geophys. Res., 108, 1-16, doi:10.1029/2002JD003296, 2003.

FAO, IIASA, ISRIC, ISSCAS, and JRC: Harmonized World Soil Database (version 1.1), FAO, Rome, Italy and IIASA, Laxenburg, Austria, 2009.

Fischer, C., Kralisch, S., Krause, P., Fink, M., and Flügel, W.: Calibration of hydrological model parameters with the JAMS framework, in: 18th World IMACS/MODSIM Congress, edited by: Anderssen, R. S., Braddock, R. D., and Newham, L. T. H., July, 866-872, Cairns, Australia, 13-17 July, 2009, available at: http://mssanz.org.au/modsim09 (last access: 10 December 2014), 2009.

Fuchs, M. C., Gloaguen, R., and Pohl, E.: Tectonic and climatic forcing on the Panj river system during the Quaternary, Int. J. Earth Sci., 102, 1985-2003, doi:10.1007/s00531-013-0916-2, 2013.

Fuchs, M. C., Gloaguen, R., Krbetschek, M., Szulc, A.: Rates of river incision across the main tectonic units of the Pamir identified using optically stimulated luminescence dating of fluvial terraces, Geomorphology, 216, 79-92, doi:10.1016/j.geomorph.2014.03.027, 2014a.

Fuchs, M. C., Gloaguen, R., Merchel, S., Pohl, E., and Sulaymonova, V. A.: Millennial erosion rates across the Pamir based on 10 Be concentrations in fluvial sediments: Dominance of topographic over climatic factors, Earth Surf. Dynam. Discuss., in press, 2014b.

Gabet, E. J., Pratt-Sitaula, B., Burbank, D. J.: Climatic controls on hillslope angle and relief in the Himalayas, Geology., 32, 629632, doi:10.1130/G20641.1, 2004.

Galy, A. and France-Lanord, C.: Higher erosion rates in the Himalaya: Geochemical constraints on riverine fluxes, Geology, 29, 23, doi:10.1130/00917613(2001)029<0023:HERITH>2.0.CO;2, 2001.

Gao, W., Gao, S., Li, Z., Lu, X. X., Zhang, M., and Wang, S.: Suspended sediment and total dissolved solid yield patterns at the headwaters of Urumqi River, northwestern China: a comparison between glacial and non-glacial catchments, Hydrol. Proc., 28, 5034-5047, doi:10.1002/hyp.9991, 2014.

Gardelle, J., Berthier, E., and Arnaud, Y.: Slight mass gain of Karakoram glaciers in the early twenty-first century, Nat. Geosci., 5, 322-325, doi:10.1038/ngeo1450, 2012.

Gardelle, J., Berthier, E., Arnaud, Y., and Kääb, A.: Region-wide glacier mass balances over the Pamir-Karakoram-Himalaya during 1999-2011, The Cryosphere, 7, 1263-1286, doi:10.5194/tc7-1263-2013, 2013.

Godard, V., Bourles, D. L., Spinabella, F., Burbank, D. W., Bookhagen, B., Fisher, G. B., Moulin, A., and Leanni, L.: Dominance of tectonics over climate in Himalayan denudation, Geology, 42, 243-246, doi:10.1130/G35342.1, 2014.

Gruber, F. E. and Mergili, M.: Regional-scale analysis of highmountain multi-hazard and risk indicators in the Pamir (Tajikistan) with GRASS GIS, Nat. Hazards Earth Syst. Sci., 13, 2779 2796, doi:10.5194/nhess-13-2779-2013, 2013.

Häckel, H.: Meteorologie, UTB: Geowissenschaften, Agrarwissenschaften, 5th edn., Ulmer UTB, Stuttgart, Germany, 1999.

Hägeli, P. and McClung, D. M.: Avalanche characteristics of a transitional snow climate - Columbia Mountains, British 
Columbia, Canada, Cold Reg. Sci. Technol., 37, 255-276, doi:10.1016/S0165-232X(03)00069-7, 2003.

Hagg, W., Braun, L., Kuhn, M., and Nesgaard, T.: Modelling of hydrological response to climate change in glacierized Central Asian catchments, J. Hydrol., 332, 40-53, doi:10.1016/j.jhydrol.2006.06.021, 2007.

Hagg, W., Hoelzle, M., Wagner, S., Mayr, E., and Klose, Z.: Glacier and runoff changes in the Rukhk catchment, upper AmuDarya basin until 2050, Global Planet. Change, 110, 62-73, doi:10.1016/j.gloplacha.2013.05.005, 2013.

Hall, D. K., Salomonson, V. V., and Riggs, G. A.: MODIS/Terra Snow Cover Monthly L3 Global 0.05Deg CMG. Version 5, 2006.

Haritashya, U. K., Bishop, M. P., Shroder, J. F., Bush, A. B. G., and Bulley, H. N. N.: Space-based assessment of glacier fluctuations in the Wakhan Pamir, Afghanistan, Climatic Change, 94, 5-18, doi:10.1007/s10584-009-9555-9, 2009.

Hergarten, C.: Investigations on land cover and land use of Gorno Badakhshan (GBAO) by means of land cover classifications derived from LANDSAT 7 data making use of remote sensing and GIS techniques, Master thesis, Universität Bern, Bern, Switzerland, 2004.

Herman, F., Seward, D., Valla, P. G., Carter, A., Kohn, B., Willett, S. D., and Ehlers, T. A.: Worldwide acceleration of mountain erosion under a cooling climate, Nature, 504, 423-426, doi:10.1038/nature12877, 2013.

Hock, R.: Temperature index melt modelling in mountain areas, J. Hydrol., 282, 104-115, doi:10.1016/S0022-1694(03)00257-9, 2003.

Huffman, G. J.: Estimates of root-mean-square random error for finite samples of estimated precipitation, J. Appl. Meteorol., 36, 1191-1201, doi:10.1175/15200450(1997)036<1191:EORMSR>2.0.CO;2, 1997.

Huffman, G. J., Adler, R. F., Arkin, P., Chang, A., Ferraro, R., Gruber, A., Janowiak, J., McNab, A., Rudolf, B., and Schneider, U.: The Global Precipitation Climatology Project (GPCP) combined precipitation dataset, B. Am. Meteorol. Soc., 78, 5-20, doi:10.1175/1520-0477(1997)078<0005:TGPCPG>2.0.CO;2, 1997.

Huffman, G. J., Adler, R. F., Bolvin, D. T., Gu, G., Nelkin, E. J., Bowman, K. P., Hong, Y., Stocker, E. F., and Wolff, D. B.: The TRMM Multisatellite Precipitation Analysis (TMPA): quasiglobal, multiyear, combined-sensor precipitation estimates at fine scales, J. Hydrometeorol., 8, 38, doi:10.1175/JHM560.1, 2007.

Hydrological Sciences Branch at NASA/Goddard Space Flight Center (GSFC/HSB): GLDAS Noah Land Surface Model L4 3 Hourly $0.25 \times 0.25^{\circ}$ Subsetted, Goddard Earth Sciences Data and Information Services Center (GES DISC), Greenbelt, Maryland, USA, available at: http://mirador.gsfc.nasa.gov/collections/ GLDAS_NOAH025SUBP_3H_001.shtml (last access: 10 December 2014), 2007.

Iida, T., Kajihara, A., Okubo, H., and Okajima, K.: Effect of seasonal snow cover on suspended sediment runoff in a mountainous catchment, J. Hydrology, 428-429, 116-128, doi:10.1016/j.jhydrol.2012.01.029, 2012.

Immerzeel, W., Droogers, P., de Jong, S., and Bierkens, M.: Largescale monitoring of snow cover and runoff simulation in Himalayan river basins using remote sensing, Remote Sens. Environ., 113, 40-49, doi:10.1016/j.rse.2008.08.010, 2009.
Immerzeel, W. W., Pellicciotti, F., and Bierkens, M. F. P.: Rising river flows throughout the twenty-first century in two Himalayan glacierized watersheds, Nat. Geosci., 6, 742-745, doi:10.1038/ngeo1896, 2013.

Immerzeel, W. W., Petersen, L., Ragettli, S., and Pellicciotti, F.: The importance of observed gradients of air temperature and precipitation for modeling runoff from a glacierized watershed in the Nepalese Himalayas, Water Resour. Res., 50, 2212-2226, doi:10.1002/2013WR014506, 2014.

Iverson, R. M.: Landslide triggering by rain infiltration, Water Resour. Res., 36, 1897-1910, doi:10.1029/2000WR900090, 2000.

Jarvis, A., Reuter, H., and Nelson, A.: Hole-filled seamless SRTM data V4, available at: srtm.csi.cgiar.org (last access: 10 December 2014), 2008.

Kamal-Heikman, S., Derry, L. A., Stedinger, J. R., and Duncan, C. C.: A simple predictive tool for lower Brahmaputra River Basin monsoon flooding, Earth Interact., 11, 1-11, doi:10.1175/EI226.1, 2007.

Kawashima, S., Ishida, T., Minomura, M., and Miwa, T.: Relations between surface temperature and air temperature on a local scale during winter nights, J. Appl. Meteorol., 39, 1570-1579, doi:10.1175/1520-0450(2000)039<1570:RBSTAA>2.0.CO;2, 2000.

Khan, S. I., Adhikari, P., Hong, Y., Vergara, H., F Adler, R., Policelli, F., Irwin, D., Korme, T., and Okello, L.: Hydroclimatology of Lake Victoria region using hydrologic model and satellite remote sensing data, Hydrol. Earth Syst. Sci., 15, 107-117, doi:10.5194/hess-15-107-2011, 2011.

Khromova, T., Osipova, G., Tsvetkov, D., Dyurgerov, M., and Barry, R.: Changes in glacier extent in the eastern Pamir, Central Asia, determined from historical data and ASTER imagery, Remote Sens. Environ., 102, 24-32, doi:10.1016/j.rse.2006.01.019, 2006.

Kralisch, S., Krause, P., Fink, M., Fischer, C., and Flügel, W.: Component based environmental modelling using the JAMS framework, in: Proceedings of MODSIM07, edited by: Oxley, L., and Kulasiri, D., 812-818, Modelling and Simulation Society of Australia and New Zealand, Christchurch, New Zealand, available at: http://www.mssanz.org.au/MODSIM07/papers/14_ s51/ComponentBasedEnvironmenta_s51_Kralisch_1.pdf (last access: 10 December 2014), 2007.

Krause, P. and Hanisch, S.: Simulation and analysis of the impact of projected climate change on the spatially distributed waterbalance in Thuringia, Germany, Adv. Geosci., 21, 33-48, doi:10.5194/adgeo-21-33-2009, 2009.

Krause, P., Biskop, S., Helmschrot, J., Flügel, W.-A., Kang, S., and Gao, T.: Hydrological system analysis and modelling of the Nam Co basin in Tibet, Adv. Geosci., 27, 29-36, doi:10.5194/adgeo27-29-2010, 2010.

Kure, S., Jang, S., Ohara, N., Kavvas, M. L., and Chen, Z. Q.: Hydrologic impact of regional climate change for the snowfed and glacierfed river basins in the Republic of Tajikistan: hydrological response of flow to climate change, Hydrol. Process., 27, 40574070, doi:10.1002/hyp.9535, 2013.

Lague, D., Hovius, N., Davy, P.: Discharge, discharge variability, and the bedrock channel profile, J. Geophys. Res., 110, F04006, doi:10.1029/2004JF000259, 2005.

Liu, T., Willems, P., Feng, X. W., Li, Q., Huang, Y., Bao, A. M., Chen, X., Veroustraete, F., and Dong, Q. H.: On the usefulness 
of remote sensing input data for spatially distributed hydrological modelling: case of the Tarim River basin in China, Hydrol. Process., 26, 335-344, doi:10.1002/hyp.8129, 2012.

Lutz, A. F., Immerzeel, W. W., Gobiet, A., Pellicciotti, F., and Bierkens, M. F. P.: Comparison of climate change signals in CMIP3 and CMIP5 multi-model ensembles and implications for Central Asian glaciers, Hydrol. Earth Syst. Sci., 17, 3661-3677, doi:10.5194/hess-17-3661-2013, 2013.

Lutz, A. F., Immerzeel, W. W., Shrestha, A. B., and Bierkens, M. F. P.: Consistent increase in High Asia's runoff due to increasing glacier melt and precipitation, Nat. Clim. Change, 4, 587-592, doi:10.1038/nclimate2237, 2014.

Maher, K. and Chamberlain, C. P.: Hydrologic regulation of chemical weathering and the geologic carbon cycle., Science, 343, 1502-4, doi:10.1126/science.1250770, 2014.

Maussion, F., Scherer, D., Finkelnburg, R., Richters, J., Yang, W., and Yao, T.: WRF simulation of a precipitation event over the Tibetan Plateau, China - an assessment using remote sensing and ground observations, Hydrol. Earth Syst. Sci., 15, 1795-1817, doi:10.5194/hess-15-1795-2011, 2011.

Maussion, F., Scherer, D., Mölg, T., Collier, E., Curio, J., and Finkelnburg, R.: Precipitation seasonality and variability over the Tibetan Plateau as resolved by the High Asia Reanalysis, J. Climate, 27, 1910-1927, doi:10.1175/JCLI-D-13-00282.1, 2014.

Ménégoz, M., Gallée, H., and Jacobi, H. W.: Precipitation and snow cover in the Himalaya: from reanalysis to regional climate simulations, Hydrol. Earth Syst. Sci., 17, 3921-3936, doi:10.5194/hess-17-3921-2013, 2013.

Mergili, M., Kopf, C., Müllebner, B., And Schneider, J. F.: Changes Of The Cryosphere And Related Geohazards In The HighMountain Areas Of Tajikistan And Austria: A Comparison, Geografiska Annaler: Series A, Physical Geography, 94, 79-96, doi:10.1111/j.1468-0459.2011.00450.x, 2012.

Merritt, W., Alila, Y., Barton, M., Taylor, B., Cohen, S., and Neilsen, D.: Hydrologic response to scenarios of climate change in sub watersheds of the Okanagan basin, British Columbia, J. Hydrol., 326, 79-108, doi:10.1016/j.jhydrol.2005.10.025, 2006.

Milliman, J. D. and Syvitski, J. P. M.: Geomorphic/Tectonic Control of Sediment Discharge to the Ocean: The Importance of Small Mountainous Rivers, J. Geology, 100, 525-544, 1992.

Mischke, S., Rajabov, I., Mustaeva, N., Zhang, C., Herzschuh, U., Boomer, I., Brown, E. T., Andersen, N., Myrbo, A., and Ito, E.: Modern hydrology and late Holocene history of Lake Karakul, eastern Pamirs (Tajikistan): a reconnaissance study, Palaeogeogr. Palaeocl., 289, 10-24, doi:10.1016/j.palaeo.2010.02.004, 2010.

Mölg, T., Maussion, F., Yang, W., and Scherer, D.: The footprint of Asian monsoon dynamics in the mass and energy balance of a Tibetan glacier, The Cryosphere, 6, 1445-1461, doi:10.5194/tc6-1445-2012, 2012.

Mölg, T., Maussion, F., and Scherer, D.: Mid-latitude westerlies as a driver of glacier variability in monsoonal High Asia, Nature Climate Change, 4, 68-73, doi:10.1038/nclimate2055, 2013.

Montgomery, D. R. and Brandon, M. T.: Topographic controls on erosion rates in tectonically active mountain ranges, Earth Planet. Sc. Lett., 201, 481-489, doi:10.1016/S0012-821X(02)00725-2, 2002.

Mostovoy, G. V., King, R. L., Reddy, K. R., Kakani, V. G., and Filippova, M. G.: Statistical estimation of daily maximum and minimum air temperatures from MODIS LST data over the State of Mississippi, GISci, Remote Sens., 43, 78-110, 2006.

$\mathrm{Mu}$, Q., Zhao, M., and Running, S. W.: Improvements to a MODIS global terrestrial evapotranspiration algorithm, Remote Sens. Environ., 115, 1781-1800, doi:10.1016/j.rse.2011.02.019, 2011.

Narzikulov, I. K. and Stanjukovič, K. V.: Atlas Tadzikskoj Sovetskoj Socialisticeskoj Respubliki, Akademija Nauk Tadžikskoj SSR, Dušanbe Sovet po Izučeniju Proizvoditel'nych Sil, Moskau, Dušanbe, Russia, 1968.

Nash, J. and Sutcliffe, J.: River flow forecasting through conceptual models part I - A discussion of principles, J. Hydrol., 10, 282 290, doi:10.1016/0022-1694(70)90255-6, 1970.

National Centers for Environmental Prediction, NOAA, US Department of Commerce, N. W. S.: NCEP FNL Operational Model Global Tropospheric Analyses, continuing from July 1999, Research Data Archive at the National Center for Atmospheric Research, Computational and Information Systems Laboratory, Boulder, CO, doi:10.5065/D6M043C6, 2000.

Nepal, S., Krause, P., Flügel, W.-A., Fink, M., and Fischer, C.: Understanding the hydrological system dynamics of a glaciated alpine catchment in the Himalayan region using the J2000 hydrological model, Hydrol. Process., 28, 1329-1344, doi:10.1002/hyp.9627, 2014.

Ollesch, G., Sukhanovski, Y., Kistner, I., Rode, M., and Meissner, R.: Characterization and modelling of the spatial heterogeneity of snowmelt erosion, Earth Surf. Proc. Land., 211, 197-211, doi:10.1002/esp.1175, 2005.

Ollesch, G., Kistner, I., Meissner, R., and Lindenschmidt, K.-E.: Modelling of snowmelt erosion and sediment yield in a small low-mountain catchment in Germany, Catena, 68, 161-176, doi:10.1016/j.catena.2006.04.005, 2006.

Palazzi, E., Hardenberg, J. V., and Provenzale, A.: Precipitation in the Hindu-Kush Karakoram Himalaya: observations and future scenarios, J. Geophys. Res.-Atmos., 118, 85-100, 2013.

Peel, M. C., Finlayson, B. L., and McMahon, T. A.: Updated world map of the Köppen-Geiger climate classification, Hydrol. Earth Syst. Sci., 11, 1633-1644, doi:10.5194/hess-11-16332007, 2007.

Pohl, E., Gloaguen, R., Seiler, R.: Remote Sensing Based Assessment of the Variability of Winter and Summer Precipitation in the Pamirs and their Effects on Hydrology and Hazards using Harmonic Time Series Analysis, Remote Sens., in review, 2015.

Prigent, C.: Precipitation retrieval from space: an overview, CR Geosci., 342, 380-389, doi:10.1016/j.crte.2010.01.004, 2010.

$\mathrm{Pu}, \mathrm{Z} ., \mathrm{Xu}, \mathrm{L}$. , and Salomonson, V. V.: MODIS/Terra observed seasonal variations of snow cover over the Tibetan Plateau, Geophys. Res. Lett., 34, L06706, doi:10.1029/2007GL029262, 2007.

R Core Team: R: A Language and Environment for Statistical Computing, R Foundation for Statistical Computing, Vienna, Austria, available at: http://www.r-project.org (last access: 10 December 2014), 2014.

Rodell, M., Houser, P. R., Jambor, U., Gottschalck, J., Mitchell, K., Meng, C. J., Arsenault, K., Cosgrove, B., Radakovich, J., Bosilovich, M., Entin, J. K., Walker, J. P., Lohmann, D., and Toll, D.: The global land data assimilation system, B. Am. Meteorol. Soc., 85, 381, doi:10.1175/BAMS-85-3-381, 2004.

Roe, G. H.: Orographic precipitation, Annu. Rev. Earth Pl. Sc., 33, 645-671, doi:10.1146/annurev.earth.33.092203.122541, 2005. 
Samaniego, L., Kumar, R., and Jackisch, C.: Predictions in a datasparse region using a regionalized grid-based hydrologic model driven by remotely sensed data, Hydrol. Res., 42, 338-355, doi:10.2166/nh.2011.156, 2011.

Scherler, D., Bookhagen, B., and Strecker, M. R.: Hillslopeglacier coupling: The interplay of topography and glacial dynamics in High Asia, J. Geophys. Res., 116, F02019, doi:10.1029/2010JF001751, 2011.

Scherler, D., Bookhagen, B., and Strecker, M. R.: Tectonic control on 10 Be-derived erosion rates in the Garhwal Himalaya, India, J. Geophys. Res.-Earth, 119, 83-105, doi:10.1002/2013JF002955, 2014.

Schiemann, R., Glazirina, M. G., and Schär, C.: On the relationship between the Indian summer monsoon and river flow in the Aral Sea basin, Geophys. Res. Lett., 34, L05706, doi:10.1029/2006GL028926, 2007.

Schwarze, R., Dröge, W., and Opherden, K.: Regional analysis and modelling of groundwater runoff components from catchments in hard rock areas, in: Regionalization in Hydrology, edited by: Diekkrüger, B., Kirkby, M. J., and Schröder, U., International Association of Hydroiogical Sciences, Braunschweig, Germany, 221-232, 1999.

Skamarock, W. C. and Klemp, J. B.: A time-split nonhydrostatic atmospheric model for weather research and forecasting applications, J. Comput. Phys., 227, 3465-3485, doi:10.1016/j.jcp.2007.01.037, 2008.

Skofronick-Jackson, G. and Weinman, J.: A physical model to determine snowfall over land by microwave radiometry, IEEE T. Geosci. Remote, 42, 1047-1058, doi:10.1109/TGRS.2004.825585, 2004.

Snyder, N. P., Whipple, K. X., Tucker, G. E, Merritts, D. J.,: Importance of a stochastic distribution of floods and erosion thresholds in the bedrock river incision problem, J. Geophys. Res., 108, 2117, doi:10.1029/2001JB001655, 2003.

Sorg, A., Bolch, T., Stoffel, M., Solomina, O., and Beniston, M.: Climate change impacts on glaciers and runoff in Tien Shan (Central Asia), Nature Climate Change, 2, 725-731, doi:10.1038/nclimate1592, 2012.

Stahl, K., Moore, R. D., Shea, J. M., Hutchinson, D., and Cannon, A. J.: Coupled modelling of glacier and streamflow response to future climate scenarios, Water Resour. Res., 44, W02422, doi:10.1029/2007WR005956, 2008.

Strahler, A., Muchoney, D., Borak, J., Friedl, M., Gopal, S., Lambin, E., and Moody, A.: MODIS Land Cover Product Algorithm Theoretical Basis Document (ATBD) MODIS Land Cover and Land-Cover Change, available at: http://modis.gsfc.nasa. gov/data/atbd/atbd_mod12.pdf (last access: 10 December 2014), 1999.

Syed, F. S., Giorgi, F., Pal, J. S., and King, M. P.: Effect of remote forcings on the winter precipitation of central southwest Asia part 1: observations, Theor. Appl. Climatol., 86, 147-160, doi:10.1007/s00704-005-0217-1, 2006.

Tahir, A. A., Chevallier, P., Arnaud, Y., and Ahmad, B.: Snow cover dynamics and hydrological regime of the Hunza River basin, Karakoram Range, Northern Pakistan, Hydrol. Earth Syst. Sci., 15, 2275-2290, doi:10.5194/hess-15-2275-2011, 2011.

Takala, M., Luojus, K., Pulliainen, J., Derksen, C., Lemmetyinen, J., Kärnä, J.-P., Koskinen, J., and Bojkov, B.: Estimating northern hemisphere snow water equivalent for climate research through assimilation of space-borne radiometer data and groundbased measurements, Remote Sens. Environ., 115, 3517-3529, doi:10.1016/j.rse.2011.08.014, 2011.

Tong, J., Dery, S. J., Jackson, P. L., and Derksen, C.: Testing snow water equivalent retrieval algorithms for passive microwave remote sensing in an alpine watershed of western Canada, Can. J. Remote Sens., 36, 74-86, 2010.

Tustison, B., Harris, D., and Foufoula-Georgiou, E.: Scale issues in verification of precipitation forecasts, J. Geophys. Res.-Atmos., 106, 11775-11784, doi:10.1029/2001JD900066, 2001.

Vanselow, K. and Samimi, C.: Predictive Mapping of Dwarf Shrub Vegetation in an Arid High Mountain Ecosystem Using Remote Sensing and Random Forests, Remote Sens., 6, 6709-6726, doi:10.3390/rs6076709, 2014.

Wan, Z.: New refinements and validation of the MODIS landsurface temperature/emissivity products, Remote Sens. Environ., 112, 59-74, doi:10.1016/j.rse.2006.06.026, 2008.

Wan, Z. and Li, Z.-L.: A physics-based algorithm for retrieving land-surface emissivity and temperature from EOS/MODIS data, IEEE T. Geosci. Remote, 35, 980-996, doi:10.1109/36.602541, 1997.

Wan, Z., Zhang, Y., Zhang, Q., and Li, Z. L.: Quality assessment and validation of the MODIS global land surface temperature, Int. J. Remote Sens., 25, 261-274, doi:10.1080/0143116031000116417, 2004.

Wood, A. W., Leung, L. R., Sridhar, V., and Lettenmaier, D. P.: Hydrologic implications of dynamical and statistical approaches to downscaling climate model outputs, Climatic Change, 62, 189216, doi:10.1023/B:CLIM.0000013685.99609.9e, 2004.

Xiao, X., Moore, B., Qin, X., Shen, Z., and Boles, S.: Large-scale observations of alpine snow and ice cover in Asia: using multitemporal VEGETATION sensor data, Int. J. Remote Sens., 23, 2213-2228, doi:10.1080/01431160110076180, 2002.

Yatagai, A., Arakawa, O., Kamiguchi, K., and Kawamoto, H.: A 44year daily gridded precipitation dataset for Asia, SOLA, 5, 137140, doi:10.2151/sola.2009-035, 2009.

Yatagai, A., Kamiguchi, K., Arakawa, O., Hamada, A., Yasutomi, N., and Kitoh, A.: APHRODITE: constructing a long-term daily gridded precipitation dataset for Asia based on a dense network of rain gauges, B. Am. Meteorol. Soc., 93, 1401-1415, doi:10.1175/BAMS-D-11-00122.1, 2012.

Yin, Z.-Y.: Using a geographic information system to improve special sensor microwave imager precipitation estimates over the Tibetan Plateau, J. Geophys. Res., 109, D03110, doi:10.1029/2003JD003749, 2004.

Zech, R., Abramowski, U., Glaser, B., Sosin, P., Kubik, P., and Zech, W.: Late quaternary glacial and climate history of the Pamir Mountains derived from cosmogenic be exposure ages, Quaternary Res., 64, 212-220, doi:10.1016/j.yqres.2005.06.002, 2005.

Zischg, A., Fuchs, S., Keiler, M., and Meiß1, G.: Modelling the system behaviour of wet snow avalanches using an expert system approach for risk management on high alpine traffic roads, Nat. Hazards Earth Syst. Sci., 5, 821-832, doi:10.5194/nhess-5-8212005, 2005. 